\title{
Seasonal variations in indoor air quality parameters and occupants self-reported physical health within a warm humid climatic environment
}

\author{
Bode Abiodun Orola* \\ Department of Architecture, Obafemi Awolowo University, Ile-Ife, Nigeria
}

Received: 15 November 2019 / Accepted: 25 March 2020

\begin{abstract}
This study examines seasonal variations in Indoor Air Quality in occupied spaces within student hostels of Obafemi Awolowo University, Nigeria, and the associated physical health effects reported by occupants. Indoor Air Quality data were obtained from 22 selected rooms, with at least two rooms selected from the nine different spatial design layouts identified in the hostel buildings. Indoor Air Quality parameters obtained were 15-minute interval data of relative humidity, as well as concentrations of carbon dioxide, total volatile organic compounds, and particulate matters. These were measured with data loggers placed at $1.0 \mathrm{~m}$ from the floor level in the centre of selected rooms. Measurements were taken in selected rooms through a period of four consecutive weeks each during the peaks of dry and wet seasons. A questionnaire, which was administered immediately at the end of the measurement period to 696 respondents, was used to capture the significant physical health symptoms as reported by the occupants, as well as information regarding their activities and use of the rooms. Significant health symptoms reported by occupants were the same across seasons. These were cold, fatigue, and headache. Indoor concentrations of carbon dioxide and particulate matters have most significant relationship with reported health symptoms.
\end{abstract}

Keywords: Dry and wet season / indoor air quality / physical health symptoms / students hostels / warm humid environment

\section{Introduction}

The significance of an acceptable quality of indoor air in occupied spaces cannot be overemphasized. One of the phenomena that has significant effect on the health of an average human is the quality of the air we breathe both outdoor and indoor [1]. More emphasis is here being laid on the indoor air quality because studies have shown that an average human spend at least $80 \%$ of his time indoor [2]. Often times, some health symptoms have been reported by occupants of certain buildings for no readily identifiable reason rather than their being exposed to the physical conditions in the buildings. Such health symptoms include irritation of the eyes, nose and throat, lethargy, headaches, nausea, dizziness, bronchial asthma, itchy eyes, itchy nose, dry skin, among others [3,4]. Although the quality of the indoor air may not be the singular cause for such observation, it has however been established that indoor air constitutes a dominant or foremost exposure route for these health symptoms [5]. This trend is perceptible not

\footnotetext{
* e-mail: orolaab@oauife.edu.ng
}

only in free running building but also within mechanically ventilated spaces $[6,7]$. While a filtering mechanism for the outdoor air that enters indoor spaces may reduce the health hazards of these contaminants in mechanically ventilated spaces, in free running buildings, concentration often reach uncontrollable levels especially when outdoor conditions are not favourable.

An acceptable indoor air is one in which there are no known contaminants at harmful concentrations as determined by cognizant authorities, and with which a substantial majority ( $80 \%$ or more) of the people exposed do not express dissatisfaction [8]. The list of these indoor air contaminants is almost inexhaustible. However, SCALE (2004) [9] showed that more than 900 different organic compounds have been detected in indoor air at different levels of concentration resulting in different health outcomes on the occupants. Each of these contaminants has different sources from the indoor spaces, they also have different concentrations which is determined by the spatial qualities of the space. These sources range from indoor finishing materials, furniture, disinfectants, household appliances as well as activities being carried out in the space. This therefore suggests that across different types of 
Table 1. Nigerian air quality standards.

\begin{tabular}{|c|c|c|c|}
\hline Pollutants & Time of average & Limit & $\begin{array}{l}\text { Health effect when } \\
\text { exposed beyond limit }\end{array}$ \\
\hline Particulates & $\begin{array}{l}\text { Daily average of daily } \\
\text { values for } 1 \text { hour. }\end{array}$ & $\begin{array}{l}250 \mu \mathrm{g} / \mathrm{m}^{3} \\
600 \mu \mathrm{g} / \mathrm{m}^{3}\end{array}$ & $\begin{array}{l}\text { Breathing/respiratory } \\
\text { problems }\end{array}$ \\
\hline $\begin{array}{l}\text { Sulphur oxides (Sulphur } \\
\text { dioxide) }\end{array}$ & $\begin{array}{l}\text { Daily average of hourly } \\
\text { values } 1 \text { hour }\end{array}$ & $\begin{array}{l}0.01 \mathrm{ppm}\left(26 \mu \mathrm{g} / \mathrm{m}^{3}\right) \\
0.1 \mathrm{ppm}\left(26 \mu \mathrm{g} / \mathrm{m}^{3}\right.\end{array}$ & Skin and lung disease \\
\hline Carbon monoxide & $\begin{array}{l}\text { Daily average of hourly } \\
\text { values 8-hourly average }\end{array}$ & $\begin{array}{l}10 \mathrm{ppm}\left(11.4 \mu \mathrm{g} / \mathrm{m}^{3}\right) \\
20 \mathrm{ppm}\left(22.8 \mu \mathrm{g} / \mathrm{m}^{3}\right)\end{array}$ & $\begin{array}{l}\text { Headache, dizziness, } \\
\text { weakness, nausea, } \\
\text { vomiting }\end{array}$ \\
\hline $\begin{array}{l}\text { Nitrogen oxides } \\
\text { (Nitrogen dioxide) }\end{array}$ & $\begin{array}{l}\text { Daily average of hourly } \\
\text { values (range) }\end{array}$ & $\begin{array}{l}0.04 \mathrm{ppm}-0.06 \mathrm{ppm} \\
\left(75.0 \mu \mathrm{g} / \mathrm{m}^{3}-113 \mu \mathrm{g} / \mathrm{m}^{3}\right)\end{array}$ & $\begin{array}{l}\text { Coughing, wheezing, eye } \\
\text { irritation, nose and } \\
\text { throat irritation }\end{array}$ \\
\hline
\end{tabular}

Source: Nigerian Federal Environmental Protection Agency, (1991) [10] and Berglund et al, (1992) [39].

Table 2. Maximum allowable concentrations for some indoor air contaminants.

\begin{tabular}{|c|c|c|}
\hline Contaminant & Maximum allowable concentration & $\begin{array}{l}\text { Health effect when exposed beyond } \\
\text { allowable concentration }\end{array}$ \\
\hline Formaldehyde & $33 \mathrm{ppb}$ (parts per billion) & Irritation of the eyes, nose and throat \\
\hline Particulate $\left(\mathrm{PM}_{2.5}\right)$ & $35 \mu \mathrm{g} / \mathrm{m}^{3}(24-\mathrm{hr})$ & Breathing/respiratory problems \\
\hline $\begin{array}{l}\text { Total Volatile Organic Compounds } \\
\text { (TVOC) }\end{array}$ & $300 \mathrm{ppb}$ (parts per billion) & $\begin{array}{l}\text { Irritation of the eyes, nose and } \\
\text { throat, nausea, difficulty in breathing }\end{array}$ \\
\hline Carbon dioxide $\left(\mathrm{CO}_{2}\right)$ & 1000 ppm (parts per million) & $\begin{array}{l}\text { Headache, dizziness, restlessness, } \\
\text { difficulty in breathing, tiredness }\end{array}$ \\
\hline Ozone & $0.070 \mathrm{ppm}$ (parts per million) (8-hr) & Increase in risk of respiratory diseases \\
\hline
\end{tabular}

Source: ASHRAE, (2019) [8] and Berglund et al. (1992) [39].

buildings and different climatic regions, the quality of the indoor air as compared with stipulated standards may vary, and that these variations may be so significant to generate widely varied physical health outcomes in occupants.

In Nigeria, the available standards regarding the several aspects of the condition of the indoor environment are not all encompassing. The guideline and standards for environmental pollution control in Nigeria provided guidelines on a wide range of environmental pollutants, but quite a few are within the armpit of the quality of the indoor environment [10]. The relevant ones are the gaseous emission and ambient air quality limitations as shown in Table 1. Moreover, the standards on air quality in Nigeria are not comprehensive enough. For example, as shown in Table 1, the standard for particulate matters only provides daily average or 24-hour average standard. No annual standard was provided. Moreover, the standard on particulate matter did not distinguish between $\mathrm{PM}_{10}$ and $\mathrm{PM}_{2.5}$. This is critical because the different categories of Particulate Matter have different health outcomes on occupants of indoor spaces. Hence, a more comprehensive standard from ASHRAE, (2019) [8] as shown in Table 2 was adopted in this study.

Based on stipulated standards, many scholars have established quantitative relationships between Indoor Air Quality (IAQ) and the occupant's health [4,11-15]. Although the studies came up with informative conclusions regarding specific latent relationships between Indoor Air Quality (IAQ) parameters and the health outcomes from the occupants, each of them has its own strength and weaknesses. In a study in United States office buildings, Apte et al. (2000) [12] employed the analysis of only $\mathrm{CO}_{2}$ concentrations to arrive at a relationship between IAQ and the health outcomes of the office occupants. This may not be comprehensive enough because many other pollutants interrelate to create a cumulative effect on the health of occupants. In a similar study by Oguntoke et al. (2010) [13], more air pollutants like $\mathrm{H}_{2} \mathrm{~S}, \mathrm{CH}_{4}, \mathrm{SO}_{2}$ and $\mathrm{NO}_{2}$ were incorporated. The study identified the causality factor for the observed effect of IAQ on the occupants' health as high dependence on fuel wood as source of energy for cooking. 
These relationships may not be generalizable as many occupants especially in urban areas do not use this type of energy [16]. Also, Turunen et al. (2014) [4] concluded that poor IAQ correlated with ventilation and temperature in classrooms, and that the correlation between headaches and measured temperature was almost at the level of significance. The study however drew these conclusions based on only measured $\mathrm{CO}_{2}$ concentrations and room temperatures. There are several other studies that are more comprehensive by considering exposure of occupants to many several air pollutants simultaneously [3,17]. Most of such studies were however carried out in offices and school environment where occupants were exposed to the indoor air for just 8 hours or less in a day $[7,11]$. Hence any conclusion from such studies may be limiting. This then calls for a comprehensive study of this relationship in the residential indoor spaces where occupants spend over $60 \%$ of their time on the average. One of such residential spaces is the students' hostels.

The main aim of this study therefore is to examine the seasonal variations in Indoor Air Quality in occupied spaces within student hostels of Obafemi Awolowo University, Ile-Ife, Nigeria, as well as the associated physical health effects as reported by the occupants. This study achieves this through a number of specific objectives. First, it identifies the significant sources of indoor air contaminants in occupied spaces within the students' hostels. Second, it examines the variations in the spaces' Indoor Air Quality across the seasons. Third, it examines the significant physical health symptoms as reported by the occupants. Fourth, it analyses the relationships between aspects of IAQ and the occupants self-reported physical health symptoms.

\section{The study area}

The studied occupied spaces are in different student hostels within the campus of Obafemi Awolowo University which is located within Ile-Ife, a small city in South-western Nigeria. The city is located between latitudes $7^{\circ} 28^{\prime} \mathrm{N}-7^{\circ}$ $34^{\prime} \mathrm{N}$ and longitudes $4^{\circ} 27^{\prime} \mathrm{E}-4^{\circ} 35^{\prime} \mathrm{E}$ with an elevation of about $275 \mathrm{~m}$ above sea level (see Fig. A2). Relevant outdoor climatic data form Nigeria Micrometeorological Experiment (NIMEX) Obafemi Awolowo University Ile-Ife, showed that, during the study period, this location combined high temperature $\left(\operatorname{mean}_{\max }\right.$ of $\left.31.4^{\circ} \mathrm{C}\right)$, high humidity $\left(\right.$ mean $_{\max }$ of $\left.83.3 \%\right)$ and low air velocity $\left(\right.$ mean $_{\max }$ of $\left.1.55 \mathrm{~m} / \mathrm{s}\right)$ with high precipitation $(1691.1 \mathrm{~mm}$ annual). This micro-climatic data from NIMEX relates well with Ile-Ife outdoor weather chart from CLIMATE-DATA. ORG as shown in the appendix (see Fig. A1).

There are a number of building components common to the spaces. These are the walls which are of sandcrete blocks rendered on both sides with cement and sand plaster, and painted with matte finish; the windows which are made of glass louver to achieve natural ventilation; the painted timber flush doors; and the roofs which are made of corrugated asbestos with asbestos ceiling. Each hostel building has study cum sleeping rooms as the main spaces with terraces and balconies and other ancillary spaces like kitchenettes, bathrooms and laundry at one end of each of the block of rooms, all accessible through a central corridor. Moreover, a significant percentage of the spaces were designed with no artificial ventilation system. However, there are some spatial and design qualities that are not the same in all the spaces. These are the floor area, the wall area, the headroom, the window to floor and window to external wall area ratios, as well as the occupancy ratio. The hostels location relative to the entire campus layout as well as the floor plan of each of the spatial design layouts is as shown in the appendix (see Plate A1).

\section{Materials and methods}

This study basically employed primary data. First, the Indoor Air Quality data was obtained from 22 selected rooms, with at least two rooms selected from the nine different spatial design layouts identified in the hostel buildings (see Appendix). The IAQ parameters data obtained included 15-minute interval data of the indoor relative humidity, carbon dioxide $\left(\mathrm{CO}_{2}\right)$ concentrations, total volatile organic compounds (TVOC) concentrations, as well as particulate matters $\left(\mathrm{PM}_{2.5}\right.$ and $\left.\mathrm{PM}_{10}\right)$ concentrations. These were measured with Air Mentor which is a 6-in-1 indoor pollutant concentration monitor (Model No.:8096-AP) placed at the work plane (about $1.0 \mathrm{~m}$ from the floor level) at the centre of each selected space (see Plate A2). This monitor can detect concentrations of carbon dioxide $\left(\mathrm{CO}_{2}\right)$, volatile organic compounds (VOCs) along with carbon monoxide $(\mathrm{CO})$, particulate matters $\left(\mathrm{PM}_{2.5}\right.$ and $\left.\mathrm{PM}_{10}\right)$, temperature and relative humidity. Its operating temperature is $5-40^{\circ} \mathrm{C}$. The particulate matter sensor can detect particle size greater than $1.0 \mu \mathrm{m}$ (i.e. $\mathrm{PM}_{2.5} / \mathrm{PM}_{10} \mu \mathrm{g} / \mathrm{m}^{3}$ ) with a range of $0-300 \mu \mathrm{g} / \mathrm{m}^{3}$ and resolution of $1.0 \mu \mathrm{g} / \mathrm{m}^{3}$. Its TVOC/Gas Pollution sensor can detect total concentration of Volatile Organic Compounds, including Alcohols, Aldehydes, Aliphatic hydrocarbons, Amines, Aromatic hydrocarbons, $\mathrm{CO}, \mathrm{CH}_{4}, \mathrm{LPG}$, Ketones, Organic acids, etc. It has a range of $125-3500 \mathrm{ppb}$ (parts per billion) and a resolution of $1.0 \mathrm{ppb}$. The $\mathrm{CO}_{2}$ sensor is NDIR (Non-dispersive Infrared) with a sensor range of 400-2000 ppm (parts per million) and resolution of $1.0 \mathrm{ppm}$. Its temperature sensor range is $-20^{\circ} \mathrm{C}$ to $80^{\circ} \mathrm{C}$ with a resolution of $0.1^{\circ} \mathrm{C}$. Its relative humidity sensor range is $0-100 \%$ with a resolution of $1.0 \%$. The measurements were taken in each of the rooms through a period of four consecutive weeks each during both the dry and wet seasons (Between January and February as well as between June and July). These are the two main seasons not only in the Ile-Ife, Nigeria but also in warm humid climates in general. Afterwards, mean values of the measured IAQ parameters were calculated for each hour of the day to capture the daily trend in each of the nine different spatial design layouts.

Second, physical characteristics of the spaces were obtained through observation, physical measurements and as-built drawings to obtain the external wall area, operable window area, window to external wall ratio, window to floor ratio, fabric thermal properties, and chemical properties of the finishes. Third, a questionnaire was used 
Table 3. Relationships between IAQ parameters concentration levels and fenestration opening rate.

\begin{tabular}{llc}
\hline & \multicolumn{2}{c}{ Percentage of windows areas always opened } \\
\hline $24 \mathrm{hr}$ average for $\mathrm{PM}_{2.5}$ concentration level & Pearson correlation & .068 \\
$24 \mathrm{hr}$ average for $\mathrm{PM}_{10}$ concentration level & Sig. (2-tailed) & .149 \\
& Pearson Correlation & .067 \\
$24 \mathrm{hr}$ average for $\mathrm{CO}_{2}$ concentration level & Sig. (2-tailed) & .153 \\
& Pearson Correlation & $.316^{* *}$ \\
$24 \mathrm{hr}$ average for TVOC concentration level & Sig. (2-tailed) & .000 \\
& Pearson Correlation & $.142^{* *}$ \\
Mean relative humidity & Sig. (2-tailed) & .002 \\
& Pearson Correlation &. $.103^{*}$ \\
\hline
\end{tabular}

to capture the significant physical health symptoms as reported by the occupants. The selected occupants were asked to indicate how frequently they observed some physical health symptoms that are related the indoor air quality as well as the frequency with which they consulted a medical doctor with respect to each health symptoms during the period when the physical measurements were taken. The health symptoms are nausea, eye irritation, skin irritation, vomiting, dizziness, headache, fatigue, sore throat, runny nose, cold, cough, and respiratory problem $[3,18]$. The frequency of observance of each symptom was ranked from 0 for "not at all", 1 for "occasionally", 2 for "more than half of the period", and 3 for "almost every day".

In order to make sure that the subjects were responding to the physically measured IAQ parameters, purposive sampling was used to select all the occupants in the selected rooms as well as the two adjoining rooms to fill the questionnaire. This amounted to 696 respondents. The questionnaire, which was filled immediately at the end of the measurement period, also elicited information regarding the activities carried out in the rooms, the occupants average length of stay in the rooms per day, use of artificial ventilation, the frequency at which occupants opened the fenestrations, occupancy ratio (floor area per occupants), among others. The same questionnaire was used to capture other intervening variables related to the personal and socio-cultural characteristics of the occupants. These were their age, gender, height, weight, smoking status and mode of dressing. The data collected were subjected to statistical analysis using the IBM SPSS Statistics 22.

\section{Results and discussion}

This study assessed the quality of the indoor air by taking physical measurements of indoor relative humidity, concentration levels of carbon dioxide $\left(\mathrm{CO}_{2}\right)$, particulates matters $\left(\mathrm{PM}_{2.5}\right.$ and $\left.\mathrm{PM}_{10}\right)$ as well as total volatile organic compound (TVOC), which is a combine concentration of compounds including alcohols, aldehydes, aliphatic hydrocarbons, amines, aromatic hydrocarbons, $\mathrm{CO}, \mathrm{CH}_{4}, \mathrm{LPG}$, ketones and organic acids. During the study, the concentrations levels of these pollutants were analyzed based on the different periods of the day which was categorized into morning (12 am to 11:59 am), afternoon (12 noon to 5:59 pm), and evening (6 pm to 11:59 pm).

\subsection{Significant sources of indoor air contaminants}

This study found that the sources of indoor air pollutants reported by the occupants were toilets, waste bins, dirty laundry and carpet, cosmetics, open drain and occupants body odour. However, analysis revealed that the most significant sources during both dry and wet seasons were the toilets and the waste bins. This is because these two sources put together were reported by $56.4 \%$ and $45 \%$ of the occupants as the most significant sources of indoor air pollutants during dry and wet seasons respectively. This is noteworthy. This is because, relative to the occupied rooms, the toilets and waste bins are outdoor sources. Whereas $81.9 \%$ of the occupants reported that they regularly carry out in the rooms an activity like cooking which generates indoor air contaminants. This identifies with Abt et al. (2000) [19] who found that outdoor particles contributed significantly to indoor particle levels.

This rating of outdoor air pollutant sources as more significant than indoor sources is however, a subjective assessment by the occupants. An objective assessment of indoor vs outdoor pollutant ratio has always been difficult due to some identified challenges like outdoor weather and pollutant concentrations, indoor ventilation and infiltration rates, source strength, and human activities [20]. However, this study showed that the ventilation and infiltration rates contributed to the dominance of outdoor contaminant sources. This was confirmed by the result of a bivariate correlation analysis between the rate at which occupants opened the fenestrations and concentration levels of each of the measured parameters. As shown in Table 3, apart from the particulate matters concentration level with relationships almost at significant level with the percentage of windows area always opened, all the other indoor air parameters have significant relationships with the fenestration opening rate. Their coefficient of correlation ranged from 0.1 to 0.32 . This was confirmed for both seasons as $76.3 \%$ and $69.3 \%$ of the occupants during dry 


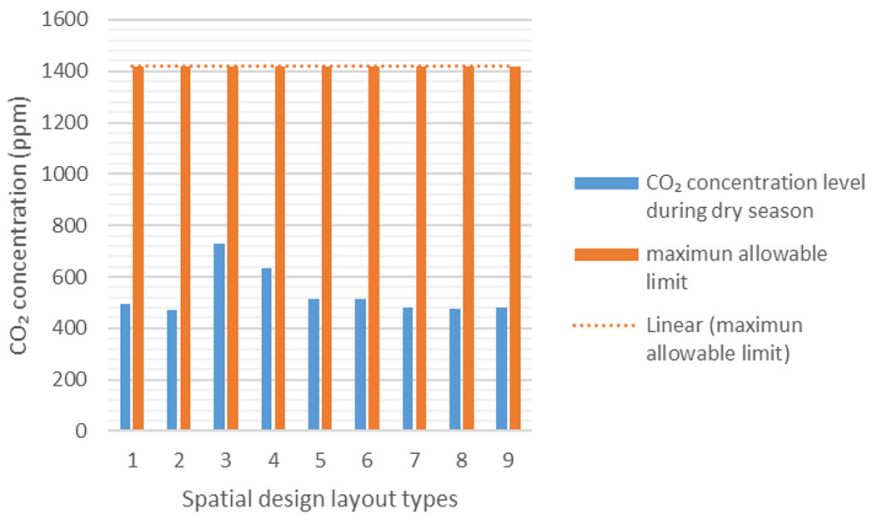

Fig. 1. $\mathrm{CO}_{2}$ concentration values in the different spatial design layouts during dry season.

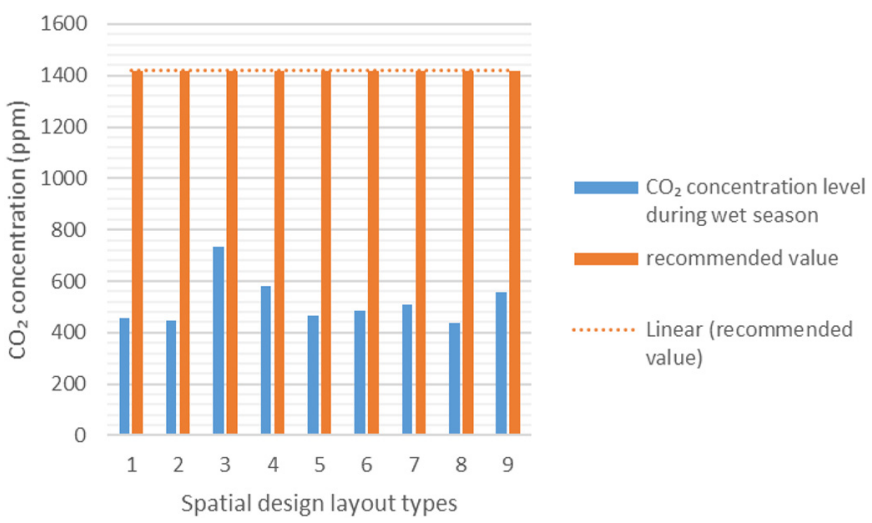

Fig. 2. $\mathrm{CO}_{2}$ concentration values in the different spatial design layouts during wet season.

Table 4. Relationship between $\mathrm{CO}_{2}$ concentration levels and aspects of room physical characteristics.

\begin{tabular}{llll}
\hline & & $\begin{array}{l}\text { Room window to } \\
\text { floor area ratio }\end{array}$ & $\begin{array}{l}\text { Room window to wall } \\
\text { area ratio }\end{array}$ \\
\hline $24 \mathrm{hr}$ average for $\mathrm{CO}_{2}$ concentration level & $\begin{array}{l}\text { Pearson Correlation } \\
\text { Sig. (2-tailed) }\end{array}$ & $-.566^{* *}$ & $-.510^{* *}$ \\
& .000 & .000 \\
\hline
\end{tabular}

and wet seasons respectively opened not less than $50 \%$ of the operable windows area during the study period.

\subsection{Indoor air quality parameters in the spaces}

\subsubsection{Assessment of indoor carbon dioxide $\left(\mathrm{CO}_{2}\right)$} concentration levels

This study found that the minimum and maximum concentration values of carbon dioxide in the spaces during the dry season ranged from $385.08 \mathrm{ppm}$ to $417.25 \mathrm{ppm}$ (part per million) and $598.60 \mathrm{ppm}$ to $924.06 \mathrm{ppm}$ respectively. The concentration was higher during the morning and evening periods of the day. This was expected in view of the daily activity pattern of the respondents, especially since occupants are the main source of $\mathrm{CO}_{2}$ indoors [21]. Observation revealed that a significant percentage of the occupants were full time students who were engaged in academic activities outside their rooms during the afternoon periods. During the wet season, the minimum and maximum concentration values of carbon dioxide in the spaces ranged from $406.42 \mathrm{ppm}$ to $421.17 \mathrm{ppm}$ and $618.88 \mathrm{ppm}$ to $927.63 \mathrm{ppm}$ respectively. The daily concentration trend was similar to that observed during the dry season where the least range of concentration levels were recorded during the afternoon period. Furthermore, it was observed that occupancy ratio in the rooms (floor area per occupant), which according to Allard (1998) [21], have a significant influence on indoor $\mathrm{CO}_{2}$ concentration levels, varied significantly across the seasons as shown in Figure 3. Consequently, an increase of just $1.58 \%$ in the mean indoor $\mathrm{CO}_{2}$ concentration level was observed during the dry season over that of the wet season.

According to ANSI/ASHRAE 62-1989 [22], comfort (odour) criteria are likely to be satisfied when the ventilation rate is set so that $1,000 \mathrm{ppm}$ of $\mathrm{CO}_{2}$ is not exceeded. However, Petty (2014) [23] showed that this is neither a ceiling level nor a time weighted average value, but a target concentration level which if exceeded, the odour criteria may not be satisfied. Moreover, the conclusion of Petty (2014) [23] revealed that concentration levels above the stipulated $1000 \mathrm{ppm}$ are not necessarily having direct health hazards. Furthermore, Schell and IntHout (2001) [24] remarked that $\mathrm{CO}_{2}$ is not considered harmful at concentration levels of 400-2000 ppm. Hence, ANSI/ASHRAE 62-1999/2002 [25] was more explicit about the standard by eliminating an absolute threshold value of $1000 \mathrm{ppm}$, but establishing a 600-700 ppm indoor/ outdoor differential concentration value. Climatic analysis revealed that average outdoor $\mathrm{CO}_{2}$ concentration during the dry season in the study area was $400.63 \mathrm{ppm}$. This therefore suggests that an acceptable $\mathrm{CO}_{2}$ concentration limit for the spaces studied should be $1100.63 \mathrm{ppm}$ during the study period. However, ANSI/ASHRAE 62-2019 [8] still showed that the acceptable value of $\mathrm{CO}_{2}$ concentration in hostel rooms should be between 1000-1200 ppm. An assessment of the measured $\mathrm{CO}_{2}$ concentration levels in line with this standard during the both seasons revealed that no single measurement went above the acceptable limit, the maximum value recorded was $924.06 \mathrm{ppm}$ for the dry season and $927.63 \mathrm{ppm}$ for the wet season. Moreover, further analysis in each of the nine different spatial design layouts as shown in Figures 1 and 2 revealed that spatial design layout types 3 and 4 have the highest mean value of $\mathrm{CO}_{2}$ concentrations during both seasons. This is noteworthy because the two design layout types have same physical properties with the lowest window to floor area and window to external wall area ratios. The result of a bivariate correlation analysis as shown in Table 4 confirmed that the rationale behind this trend is strongly linked to these aspects of the physical characteristics of the rooms. The 
Table 5. Concentration levels of particulate matters during the dry season.

\begin{tabular}{lllllllll}
\hline & $\begin{array}{l}\text { Mean } \\
\text { morning } \\
\mathrm{PM}_{2.5}\end{array}$ & $\begin{array}{l}\text { Mean } \\
\text { afternoon } \\
\mathrm{PM}_{2.5}\end{array}$ & $\begin{array}{l}\text { Mean } \\
\text { evening } \\
\mathrm{PM}_{2.5}\end{array}$ & $\begin{array}{l}\text { 24 hr } \\
\text { average } \\
\text { for } \mathrm{PM}_{2.5}\end{array}$ & $\begin{array}{l}\text { Mean } \\
\text { morning } \\
\mathrm{PM}_{10}\end{array}$ & $\begin{array}{l}\text { Mean } \\
\text { afternoon } \\
\mathrm{PM}_{10}\end{array}$ & $\begin{array}{l}\text { Mean } \\
\text { evening } \\
\mathrm{PM}_{10}\end{array}$ & $\begin{array}{l}24 \mathrm{hr} \\
\text { average } \\
\text { for } \mathrm{PM}_{10}\end{array}$ \\
\hline Mean & 142.8548 & 146.3944 & 164.6278 & 151.2923 & 496.7460 & 512.0674 & 536.2743 & 515.0292 \\
Minimum & 21.15 & 5.38 & 9.25 & 16.62 & 94.25 & 23.42 & 59.75 & 95.53 \\
Maximum & 322.85 & 300.96 & 368.21 & 306.67 & 820.52 & 797.46 & 868.00 & 787.40 \\
\hline
\end{tabular}

Table 6. Concentration levels of particulate matters during the wet season.

\begin{tabular}{lllllllll}
\hline & $\begin{array}{l}\text { Mean } \\
\text { morning } \\
\mathrm{PM}_{2.5}\end{array}$ & $\begin{array}{l}\text { Mean } \\
\text { afternoon } \\
\mathrm{PM}_{2.5}\end{array}$ & $\begin{array}{l}\text { Mean } \\
\text { evening } \\
\mathrm{PM}_{2.5}\end{array}$ & $\begin{array}{l}24 \mathrm{hr} \\
\text { average } \\
\text { for } \mathrm{PM}_{2.5}\end{array}$ & $\begin{array}{l}\text { Mean } \\
\text { morning } \\
\mathrm{PM}_{10}\end{array}$ & $\begin{array}{l}\text { Mean } \\
\text { afternoon } \\
\mathrm{PM}_{10}\end{array}$ & $\begin{array}{l}\text { Mean } \\
\text { evening } \\
\mathrm{PM}_{10}\end{array}$ & $\begin{array}{l}\text { 24hr } \\
\text { average } \\
\text { for } \mathrm{PM}_{10}\end{array}$ \\
\hline Mean & 27.4380 & 20.8883 & 26.5857 & 24.9706 & 173.1985 & 121.0077 & 130.9613 & 141.7225 \\
Minimum & 7.88 & 5.21 & 4.08 & 5.72 & 57.21 & 29.25 & 21.54 & 36.00 \\
Maximum & 42.44 & 43.46 & 84.21 & 42.29 & 268.38 & 179.67 & 279.87 & 215.78 \\
\hline
\end{tabular}

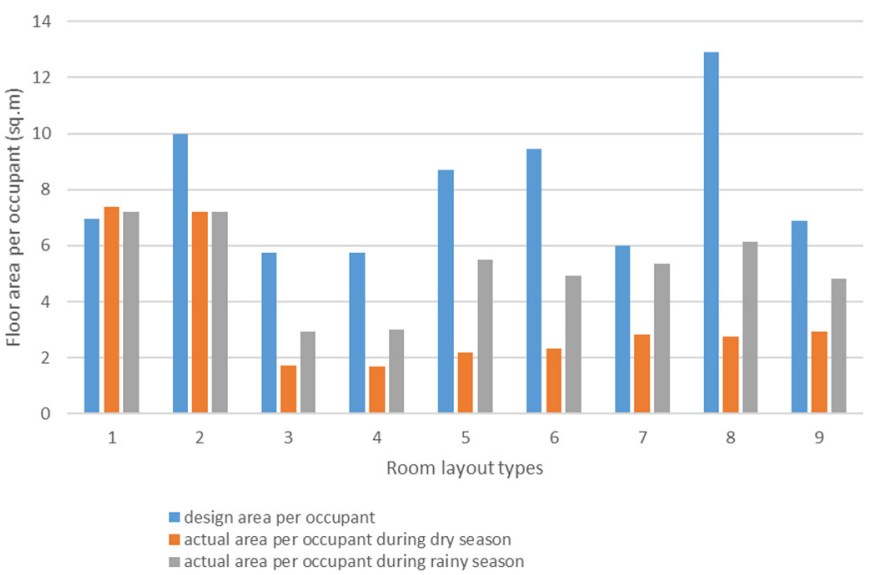

Fig. 3. Occupancy ratios in the different design spatial layouts across the seasons.

table showed that $\mathrm{CO}_{2}$ concentration levels in the rooms are inversely related to both the window to floor area ratio as well as the window to external wall area ratio at $\rho<0.1$. This agrees with Gratia et al. (2004) [26] and Karava et al. (2011) [27], especially since the rooms are designed to be naturally ventilated. Furthermore, this study confirmed a significant inverse relationship between $\mathrm{CO}_{2}$ concentration levels and occupancy ratio (floor area per occupant) at $\rho<0.1$ and correlation coefficient of 0.48 . However, with the earlier reported significant increase in the floor area per occupant during the wet season, the increase in mean $\mathrm{CO}_{2}$ concentration levels during the dry season was not commensurately significant as suggested by Allard (1998) [21]. The justification for this was explored by carrying out a comparative analysis of possible variables that could be the causality factors across the seasons. Such variables included activities carried out in the spaces, average length of daily stay in the spaces, frequency of fenestrations opening, use of curtain for the windows, state of the fly screen, use of artificial ventilation in the spaces as well as outdoor $\mathrm{CO}_{2}$ concentration levels. A significantly similar trends across the seasons was observed in all these variables but two. First, occupants who opened less than $50 \%$ of their window area increased in the wet season by $7 \%$, and second, occupants who used no form of artificial ventilation increased by $20.8 \%$ during the wet season. The variance in these two variables explains the reason why there was no significant decrease in the $\mathrm{CO}_{2}$ concentration levels in the occupied spaces during the wet season despite the significant reduction in the occupancy ratio.

\subsubsection{Assessment of indoor particulate matters concentration levels}

The indoor concentration levels of particulate matters of two different sizes in the occupied spaces were assessed. These were $\mathrm{PM}_{2.5}$ and $\mathrm{PM}_{10}$. Tables 5 and 6 showed the ranges of the minimum and the maximum concentration levels of $\mathrm{PM}_{2.5}$ and $\mathrm{PM}_{10}$ during the dry and wet seasons respectively in $\mu \mathrm{g} / \mathrm{m}^{3}$. It was observed that during the dry season the mean concentration level of $\mathrm{PM}_{2.5}$ was lowest in the morning period $\left(142.85 \mu \mathrm{g} / \mathrm{m}^{3}\right)$ and highest in the evening period $\left(164.63 \mu \mathrm{g} / \mathrm{m}^{3}\right)$. The same trend was observed for $\mathrm{PM}_{10}$ with mean concentration values for morning and evening periods being $496.75 \mu \mathrm{g} / \mathrm{m}^{3}$ and $536.27 \mu \mathrm{g} / \mathrm{m}^{3}$ respectively. The trend was slightly different during the wet season with mean concentration values of both $\mathrm{PM}_{2.5}$ and $\mathrm{PM}_{10}$ being at the lowest in the afternoon and highest in the morning.

A comparison of the mean 24 hours' concentration levels of both $\mathrm{PM}_{2.5}$ and $\mathrm{PM}_{10}$ during the dry season with the standard showed that it was more than the maximum allowable concentration level by between $200 \%$ and $300 \%$. This was comparable with the findings of Akpofure (2015) [15] and Ite et al. (2017) [17] who carried out similar studies 
Table 7. Relationship between floor area per occupants and particulate matter concentrations.

\begin{tabular}{llll}
\hline & & $\begin{array}{l}24 \mathrm{hr} \text { average concentration } \\
\text { for } \mathrm{PM}_{2.5}\end{array}$ & $\begin{array}{l}24 \mathrm{hr} \text { average concentration } \\
\text { for } \mathrm{PM}_{10}\end{array}$ \\
\hline Floor area per occupant & Pearson Correlation & -.437 & -.415 \\
& Sig. (2-tailed) & .000 & .000 \\
\hline
\end{tabular}
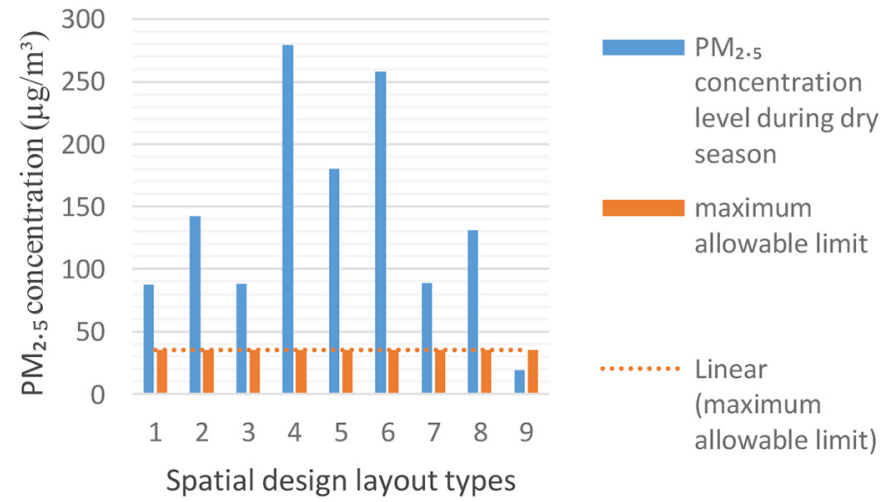

Fig. 4. $\mathrm{PM}_{2.5}$ concentration levels in the different spatial design layouts during dry season.

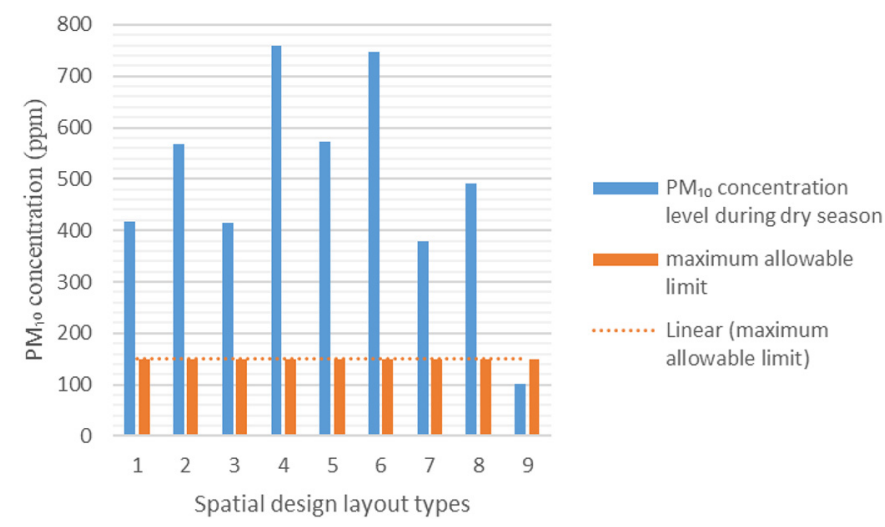

Fig. 5. $\mathrm{PM}_{10}$ concentration levels in the different spatial design layouts during dry season.

within a similar climatic environment. The reason for the high concentration levels suggested by the studies were however not identifiable with this study. While Akpofure (2015) [15] linked it to the form of domestic fuels (firewood, wood charcoal and sawdust) used for cooking by the occupants, the result of Ite et al. (2017) [17] could be linked to the air-conditioned context within which the study was done. However, during the wet season, the mean 24-hour concentration level for both $\mathrm{PM}_{2.5}$ and $\mathrm{PM}_{10}$ were below the standards maximum allowable limits. This was different from the observation during the dry season. Further analysis showed that there was a significant change in the trend of some of the variables that could be responsible for this across the seasons. These included use of curtain for the windows, state of the fly screen, use of

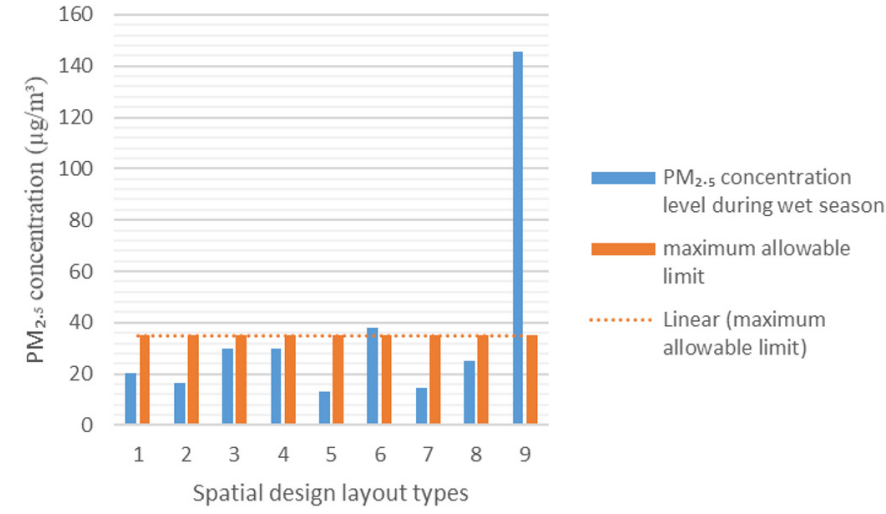

Fig. 6. $\mathrm{PM}_{2.5}$ concentration levels in the different spatial design layouts during wet season.

artificial ventilation in the spaces, average length of daily stay in the spaces, percentage of windows always opened and floor area per occupant A correlation analysis revealed that two out of all these variables had significant inverse relationship with the 24 hours' concentration levels of both $\mathrm{PM}_{2.5}$ and $\mathrm{PM}_{10}$ at $\rho<0.01$. However, the floor area per occupant was with the higher correlation coefficients of between 0.42 and 0.44 as shown in Table 7 . This therefore showed that as the floor area per occupant increased during the wet season, that reduced sources of emission of the particulate matters in the spaces and hence reduced the concentration levels below the maximum allowable limits. Moreover, analysis of the mean concentration values of the Particulate Matters in each different spatial design layouts revealed that during the dry season, room layout types 1 to 8 had mean concentration values higher than the maximum allowable concentration level. The trend is as shown in Figures 4 and 5. It was only room layout type 9 that has mean value that was lower than the recommended value. The reverse was observed during the wet season as shown in Figures 6 and 7 . The mean concentration values in spatial design layouts 1-8 reduced significantly while that in spatial design layout 9 increased. This could not be linked with the physical characteristics of the spaces because room layout type 9 was not at great variance with other room layout types regarding this. Analysis revealed that this was traceable to occupants' activities and use of the space. This is because while percentage of occupants who regularly used one form of artificial ventilation system (Table fan and standing fan) increased marginally in other spatial design layout, the percentage for occupants of layout type 9 reduced by $9.5 \%$. This corroborates Holmberg and Chen (2003) [28] who concluded that 
Table 8. Concentration levels of total volatile organic compounds during the dry season.

\begin{tabular}{lllll}
\hline & $\begin{array}{l}\text { Mean morning } \\
\text { TVOCs } \\
\text { concentration }\end{array}$ & $\begin{array}{l}\text { Mean afternoon } \\
\text { TVOCs } \\
\text { concentration }\end{array}$ & $\begin{array}{l}\text { Mean evening } \\
\text { TVOCs } \\
\text { concentration }\end{array}$ & $\begin{array}{l}\text { 24 hr average } \\
\text { for TVOC } \\
\text { concentration }\end{array}$ \\
\hline Mean & 199.6594 & 180.1761 & 223.7375 & 201.1910 \\
Minimum & 126.04 & 125.00 & 125.61 & 127.38 \\
Maximum & 372.27 & 355.45 & 393.75 & 360.27 \\
\hline
\end{tabular}

Table 9. Concentration levels of total volatile organic compounds during the wet season.

\begin{tabular}{lllll}
\hline & $\begin{array}{l}\text { Mean morning } \\
\text { TVOCs } \\
\text { concentration }\end{array}$ & $\begin{array}{l}\text { Mean afternoon } \\
\text { TVOCs } \\
\text { concentration }\end{array}$ & $\begin{array}{l}\text { Mean evening } \\
\text { TVOCs } \\
\text { concentration }\end{array}$ & $\begin{array}{l}\text { 24 hr average } \\
\text { for TVOCs } \\
\text { concentration }\end{array}$ \\
\hline Mean & 207.9950 & 172.0754 & 200.1750 & 193.4151 \\
Minimum & 138.64 & 130.08 & 135.08 & 136.38 \\
Maximum & 332.27 & 222.38 & 261.58 & 260.20 \\
\hline
\end{tabular}

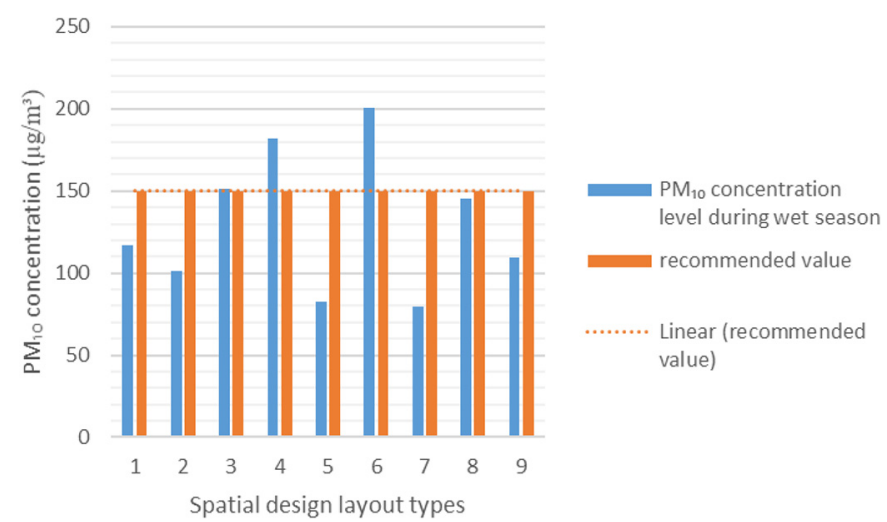

Fig. 7. $\mathrm{PM}_{10}$ concentration levels in the different spatial design layouts during wet season.

displacement ventilation systems modified with a low-zone particle exhaust can decrease particle concentrations in the breathing zone.

\subsubsection{Assessment of indoor total volatile organic compounds concentration levels}

An assessment of the indoor concentration levels of the total volatile organic compounds (TVOCs) was also carried out. This study was not able to assess the different organic compounds separately. The assessment was based on the concentration level of a number of organic compounds combined. These included alcohols, aldehydes, aliphatic hydrocarbons, amines, aromatic hydrocarbons, carbon monoxide $(\mathrm{CO})$, methane $\left(\mathrm{CH}_{4}\right), \mathrm{LPG}$, ketones and organic acids. The minimum and maximum concentration levels as well as the 24-hour mean concentration values in parts per billion (ppb) for both seasons are as shown in Tables 8 and 9. The Tables showed that, during the dry season, the mean concentration level was lowest during the

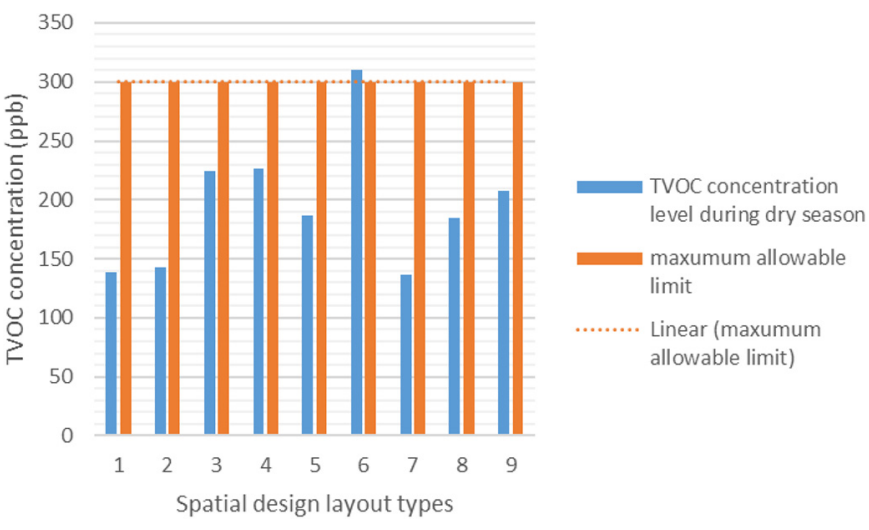

Fig. 8. TVOC concentration levels in the different spatial design layouts during dry season.

afternoon period and highest during the evening period, while during the wet season, it was lowest during the afternoon period and highest during the morning period.

A comparison of the mean 24 hours' concentration level with the standard in each of the spatial design layout types during both seasons showed that it was within the maximum allowable concentration level of $300 \mathrm{ppb}$ for a significant period of time during the study. The trend is as shown in Figures 8 and 9. Moreover, this study observed that the 24 hours mean concentration level in the spaces during the wet season was lower than that of the dry season by $3.86 \%$. Further analysis revealed that the most significant factor responsible for this was the increase in the floor area per occupant in the wet season as against the dry season. This study found a significant inverse relationship between the 24 hours mean concentration level of TVOC during the entire study period (both dry and wet seasons) and the occupancy ratio (floor area per occupant) at $\rho<0.01$ with correlation coefficient of 0.45 . 
Table 10. Indoor relative humidity values during the dry season.

\begin{tabular}{llll}
\hline & $\begin{array}{l}\text { Mean morning } \\
\text { relative humidity }\end{array}$ & $\begin{array}{l}\text { Mean afternoon } \\
\text { relative humidity }\end{array}$ & $\begin{array}{l}\text { Mean evening } \\
\text { relative humidity }\end{array}$ \\
\hline Mean & 61.4349 & 41.0600 & 51.9778 \\
Minimum & 42.25 & 26.83 & 34.54 \\
Maximum & 75.40 & 68.54 & 66.04 \\
\hline
\end{tabular}

Table 11. Indoor relative humidity values during the wet season.

\begin{tabular}{llll}
\hline & $\begin{array}{l}\text { Mean morning } \\
\text { relative humidity }\end{array}$ & $\begin{array}{l}\text { Mean afternoon } \\
\text { relative humidity }\end{array}$ & $\begin{array}{l}\text { Mean evening } \\
\text { relative humidity }\end{array}$ \\
\hline Mean & 86.1800 & 82.3199 & 85.2506 \\
Minimum & 77.83 & 76.13 & 74.58 \\
Maximum & 91.02 & 91.11 & 91.46 \\
\hline
\end{tabular}

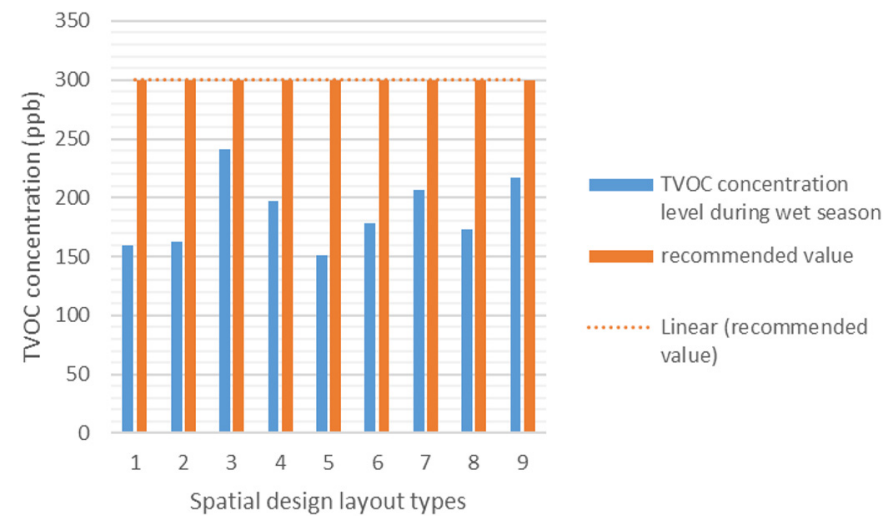

Fig. 9. TVOC concentration levels in the different spatial design layouts during wet season.

This showed that the higher the floor area per occupant, the lower the concentration level of TVOC in the occupied spaces. This, in essence, confirmed Ekwevugbe et al. (2012) [29]. The study, through experimental measurements, showed that volatile organic compounds (VOC) measurements could be useful for occupancy tracking. The study even concluded that volatile organic compound measurements produced a more obvious indication of space occupancy than $\mathrm{CO}_{2}$ measurements. This showed a strong link between TVOC concentrations and the floor area per occupant in occupied spaces.

\subsubsection{Assessment of indoor relative humidity}

The results for the mean relative humidity for the morning, afternoon and evening periods of the day during both seasons are shown in Tables 10 and 11. The Table further showed the minimum and maximum values. This was similar to the findings of Olanipekun (2014) [30] in the same climatic region during a dry season. The study found that the minimum and maximum indoor relative humidity in the area during the dry season were $30.8 \%$ and $75.5 \%$ respectively.

For acceptable condition in indoor spaces, ASHRAE Standard 55-2017 [31] recommended a range of relative humidity that is between $30 \%$ and $70 \%$. A comparison of this with the measured relative humidity in the spaces during the dry season showed that they generally met the standards. However, an acceptable relative humidity was not recorded in the spaces at all times during this season. Analysis showed that measured relative humidity fell within the recommended range for $100 \%$ of the times only during the evening period. In the morning period, measured relative humidity was above recommended range during $31.6 \%$ of the time, while in the afternoon period it was lower than the recommended range during $12.1 \%$ of the time. The trend is however different during the wet season when measured relative humidity in the spaces failed to meet the standards. An acceptable relative humidity was not recorded in the spaces at all times during the wet season. Measured relative humidity fell above the recommended range for $100 \%$ of the times throughout the wet season. Analysis revealed that this trend was due to an inverse significant relationship between indoor air temperature and indoor relative humidity observed during this study. This corroborates Nguyen and Dockery (2016) [32] who found that the shape of the indoor-to-outdoor temperature and humidity relationships varied across seasons and that there was large variation in indoor relative humidity between seasons.

\subsection{Occupants self-reported physical health symptoms}

The respondents were not specifically asked whether they had a cold or flu at the exact time of the measurements. They were however asked to rate their general physical health status or their general physical wellbeing. For this, a significant $78.1 \%$ gave a rating of between "Good" and Excellent. It was observed that during the dry season, physical health symptoms with significantly high 
Table 12. Frequency of observing IAQ related health symptoms among respondents.

\begin{tabular}{lll}
\hline Health symptoms & $\begin{array}{l}\text { Percentage of occupant } \\
\text { observing health symptoms } \\
\text { during dry season }\end{array}$ & $\begin{array}{l}\text { Percentage of occupant observing } \\
\text { health symptoms during } \\
\text { wet season }\end{array}$ \\
\hline Nausea & 19.4 & 12.6 \\
Eye irritation & 28.9 & 24.4 \\
Skin irritation & 33.5 & 32.1 \\
Vomiting & 5.8 & 5.3 \\
Dizziness & 32 & 23.4 \\
Headache & $\mathbf{6 2 . 7}$ & $\mathbf{5 8 . 9}$ \\
Fatigue & $\mathbf{6 5}$ & $\mathbf{6 2}$ \\
Sore throat & 32 & 22.4 \\
Runny nose & $\mathbf{5 6}$ & 38.6 \\
Cold & $\mathbf{7 1 . 4}$ & $\mathbf{6 8 . 2}$ \\
Cough & $\mathbf{5 0 . 8}$ & 35.5 \\
Respiratory problem & 15 & 10 \\
\hline
\end{tabular}

percentage of observation amongst the respondents were cold $(71.4 \%)$, fatigue $(65 \%)$, headache $(62.7 \%)$, runny nose $(56 \%)$ and cough $(50.8 \%)$ as shown in Table 12 . This observation was similar to that of Wong and Jan (2003) [18] carried out during the dry season in a similar climatic region, as well as that of Turunen et al. (2014) [4] carried out during the summer of a cold climatic region. The studies found that fatigue, runny nose, headache, cough and cold were the most common health symptoms reported by respondents. Although the studies were carried out in indoor environments where occupants spent less than $37 \%$ of the time they spend indoors. This study further observed that the percentage of respondents who reported these significant physical health symptoms for either more than half of the study period and almost every day ranged from $11.6 \%$ for headache to $20.3 \%$ for cold. Furthermore, the physical health symptom with the highest frequency of observation was cold, with $8.7 \%$ of the respondents reportedly observed it almost every day during the dry season. This was closely followed by runny nose with $5.8 \%$ of the respondents. During the wet season, physical health symptoms with significantly high percentage of observation amongst the respondents were cold $(68.2 \%)$, fatigue $(62 \%)$ and headache $(58.9 \%)$ as also shown in Table 12. This was similar to the observation during the dry season apart from the lower prevalence of runny nose and cough during the wet season. This observation was also similar to Wong and Jan (2003) [18] as well as Turunen et al. (2014) [4] as earlier discussed. However, during the wet season, a lower percentage of respondents observed the three most significant physical health symptoms, with the differences ranging from $3 \%$ to $3.8 \%$. Moreover, the percentage of respondents who observed these significant physical health symptoms during wet season for either more than half of the study period and almost every day ranged from $7.7 \%$ for headache to $16.2 \%$ for cold. This was also lower than the observed frequencies in the dry season. Additionally, just like during the dry season, the physical health symptom with the highest frequency of observation was cold, with
$6.2 \%$ of the respondents reportedly observing it almost every day during the wet season. Unlike during the dry season, this was closely followed by fatigue with $4.3 \%$ of the respondents. However, the respondents were not asked if the identified symptoms improved when they were outside the rooms.

Analysis revealed that room layout type number 4 consistently has the highest percentage of occupants that observed the most significant physical health symptoms almost every day during the study period. For cold it was $17.9 \%$, for fatigue it was $7.1 \%$, and for headache it was also $7.1 \%$. Almost the same trend was observed when the percentage of occupants who observed these same health symptoms for more than half of the period was considered. This study found that this has a strong link with the high concentrations of some of the measured indoor air quality parameters in this particular room layout type. As earlier discussed, not only were the mean values of $\mathrm{PM}_{2.5}$ and $\mathrm{PM}_{10}$ within this room layout type higher than the maximum allowable during the dry season by $698 \%$ and $406 \%$ respectively, they were also the highest out of all the room layout types. Also, the mean $\mathrm{CO}_{2}$ concentration measured in this same room layout type was also the highest during the dry season. Furthermore, this study found that among the respondents, the greatest percentage of those who observed the significant health symptoms for more than half of the time and almost every day were among those of ages between 15 and 17 years. It was $29.5 \%$ for cold, $25 \%$ for fatigue, and $20.4 \%$ for headache. Moreover, this study also observed that the percentage of respondents that observed the three highlighted health symptoms almost every day during the study was reducing with increase in the age groups of the respondents as shown in Figure 10. This agrees with Smedje et al. (1997) [33] who concluded that age of occupants was a significant factor when predicting their response to the quality of the indoor air. It also confirms Sakellaris et al. (2016) [34]. The study showed that the effect of Indoor Air Quality is more significant among the 
Table 13. Relationships between measured IAQ parameters and physical health symptoms in occupants during dry season.

\begin{tabular}{lll}
\hline Symptoms & Influencing IAQ parameters & Significance level $(\rho)$ \\
\hline Skin irritation & Relative humidity & 0.000 \\
Dizziness & Relative humidity & 0.003 \\
Sore throat & Total volatile organic compound concentration & 0.024 \\
Runny nose & Carbon dioxide concentration & 0.000 \\
Cold & Carbon dioxide concentration & 0.000 \\
Cough & Carbon dioxide concentration & 0.000 \\
\hline
\end{tabular}

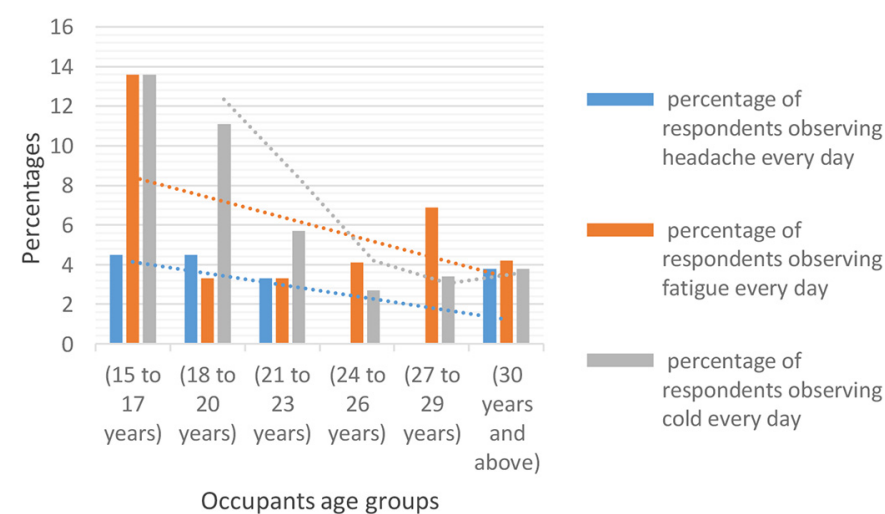

Fig. 10. Relationship between observance of health symptoms and occupants age.

youngest occupants as compared to the middle age occupants. Since respondents of ages between 15 and 17 are a significant percentage of occupants of the indoor environment in student hostels (9.8\% in this study), this study therefore suggests that they should be given special attention during the design of new hostels or during allocation of existing ones.

\subsection{Relationships between aspects of IAQ and occupants self-reported physical health symptoms}

This study established some relationships between some specific indoor air quality parameters and some physical health symptoms as reported by the occupants. Table 13 showed some of these relationships during dry season. The table revealed that the most significant relationships are between skin irritation and relative humidity, as well as cough and carbon dioxide concentration levels. It is also noteworthy that $\mathrm{CO}_{2}$ concentration have significant relationships with the highest number of self-reported physical health symptoms in the dry season. This substantiated the findings of Prill (2000) [35] who concluded that individuals in schools and offices with elevated $\mathrm{CO}_{2}$ concentrations tend to report drowsiness, lethargy and a general sense that the air is stale. These relationships between the health symptoms and $\mathrm{CO}_{2}$ concentration are noteworthy, especially since its mean concentration value during the study did not exceed allowable limit of $1000 \mathrm{ppm}$ according to ASHRAE standard. This is however similar to the findings of Apte et al, (2000) [12]. The study found that in no case was the indoor average or the peak indoor $\mathrm{CO}_{2}$ extraordinarily high, with only just one out of the 41 buildings studied having absolute indoor $\mathrm{CO}_{2}$ concentration above 1000 ppm. However, Apte et al. (2000) [12] still reported some statistically significant dose-response relationships between differential in indoor/outdoor $\mathrm{CO}_{2}$ concentration values and some health symptoms in occupants. The same trend was reported by Wong and Jan (2003) [18]. The study found the levels of $\mathrm{CO}_{2}$ recorded to be between 662 and $703 \mathrm{ppm}$ (which was below allowable limits) and still concluded that this level was adequately significant to cause physiological effects like fatigue, drowsiness and lack of concentration in occupants. A similar observation in this present study is calling to question the credibility and universality of both the standard allowable limit of $1000 \mathrm{ppm}$ and the indoor/outdoor differential of between 600 and $700 \mathrm{ppm}$. It was earlier indicated that the main source of $\mathrm{CO}_{2}$ in the spaces is indoor and not outdoor. Hence, floor area per occupant should be taken as a significant consideration when designing hostel buildings and similar building types. This is because it influences the level of concentration of $\mathrm{CO}_{2}$ in occupied spaces, this in turn significantly influence self-reported physical health symptoms in occupants. This is supporting the findings of Haverinen-Shaughnessy et al. (2015) [36]. The study reported that among others, ventilation rates, which was measured in the study with $\mathrm{CO}_{2}$ concentration levels, has the most significant relationship with occupants' health among measured Indoor Environmental Quality parameters. It also agreed with Bae et al. (2017) [37]. The study found that indoor air quality parameters were among those with the highest rank by respondents in an office building regarding the impact of Indoor Environmental Quality parameters on their health. The similarity in the observations is noteworthy because the studies were done within different environments. While Haverinen-Shaughnessy (2015) [36] was done within a school classroom environment, Bae et al. (2017) [37] was done within an office environment. In those environments, occupants spend fewer time than the time they spend in their residences. An observation of similar trends in these various environments suggests that the quality and components of the indoor air, especially the $\mathrm{CO}_{2}$ concentration, is one of the significant factors to be considered when designing similar buildings. 
Table 14. Relationships between measured IAQ parameters and physical health symptoms in occupants during wet season.

\begin{tabular}{lll}
\hline Symptoms & $\begin{array}{l}\text { Influencing IEQ } \\
\text { parameters }\end{array}$ & $\begin{array}{l}\text { Significance } \\
\text { level }(\rho)\end{array}$ \\
\hline Eye irritation & $\mathrm{PM}_{10}$ concentration & 0.002 \\
Vomiting & Relative humidity & 0.014 \\
\hline
\end{tabular}

Similarly, during the wet season, some significant relationships between specific indoor air quality parameters and some physical health symptoms as reported by the occupants were established as shown in Table 14. The table revealed that the most significant relationships were between $\mathrm{PM}_{10}$ concentration and eye irritation, as well as between relative humidity and vomiting. This result showed that $\mathrm{CO}_{2}$ concentration levels have less significant impact on observed health symptoms during the wet season. This was traceable to the reduction in the mean $\mathrm{CO}_{2}$ concentration levels during the wet season as a result of the increase in floor area per occupant. This therefore suggests why the significance of the effect of $\mathrm{CO}_{2}$ concentration level on the observed physical health symptoms diminished during the wet season. Finally, it is also noteworthy that the impact of relative humidity was not more prominent during wet season despite having recorded values higher than dry season. This corroborated the findings of Wolkoff, (2018) [38] who concluded that elevated indoor Relative Humidity may even reduce indoor air quality related complaint rates and favour performance of occupants of indoor spaces.

\section{Conclusion}

This study established that outdoor air pollutant sources were very significant to indoor air quality, and that variations in indoor concentrations of IAQ parameters across dry and wet seasons were due, not only to changes in climatic conditions across seasons, but also to changes in occupants' activities like frequency of fenestration opening, use of artificial ventilation, and floor area per occupant. This was especially confirmed regarding indoor concentrations of $\mathrm{CO}_{2}$, TVOC and the Particulate Matters. Inadequate floor area per occupant was a significant contributor to the increase in the concentration of these indoor air pollutants and consequently to more frequent observance of health symptoms. Despite the variations in IAQ parameters across the dry and wet seasons, the significant physical health symptoms reported by the occupants were the same across seasons. These were cold, fatigue, and headache. The frequency of observation of these health symptoms however were consistently higher during the dry season; were higher among occupants of ages less than 18 years; and were reducing with increase in occupants age.

\section{Implication and inferences}

In view of the conclusion of this study that indoor concentrations of $\mathrm{CO}_{2}$ and $\mathrm{PM}_{10}$ have the most significant relationship with reported physical health symptoms at $\rho<0.01$, identified sources of these significant indoor air pollutants have to be given priority when mitigating physical health effects of indoor air quality on occupants within residential building in general and students' hostels in particular. However, since there were significant variations in concentrations of $\mathrm{CO}_{2}$ during different period of the day, it is suggested that further research should be carried out regarding likely similar variation in the observance of the identified significant physical health symptoms during different periods of the day.

The author wish to acknowledge the contribution of the Nigerian Tertiary Education Trust Fund (TETFUND), Obafemi Awolowo University, Ile-Ife, Nigeria sector, for making available the fund used to procure all the instruments used for the measurements of indoor air parameters during the study period.

\section{References}

1. F. Wu, D. Jacobs, C. Mitchell, D. Miller, M.H. Karol, Improving indoor environmental quality for public health: impediments and policy recommendations, Environ. Health Perspect. 115, 953-957 (2007)

2. T. Godish, Indoor environmental quality (CRC Press, 2016)

3. S.J. Reynolds, D.W. Black, S.S. Borin et al., Indoor environmental quality in six commercial office buildings in the Midwest United States, Appl. Occup. Environ. Hygiene 16, 1065-1077 (2001)

4. M. Turunen, O. Toyinbo, T. Putus et al., Indoor environmental quality in school buildings, and the health and wellbeing of students, Int. J. Hygiene Environ. Health 217, 733-739 (2014)

5. J. Sundell, On the history of indoor air quality and health, Indoor Air 14, 51-58 (2004)

6. B.F. Yu, Z.B. Hu, M. Liu, H.L. Yang, Q.X. Kong, Y.H. Liu, Review of research on air-conditioning systems and indoor air quality control for human health, Int. J. Refrigerat. 32, 3-20 (2009)

7. K. Azuma, K. Ikeda, N. Kagi, U. Yanagi, H. Osawa, Evaluating prevalence and risk factors of building-related symptoms among office workers: seasonal characteristics of symptoms and psychosocial and physical environmental factors, Environ. Health Prevent. Med. 22, 38 (2017)

8. ANSI/ASHRAE 62.1-2019: Ventilation for acceptable indoor air quality. American Society of Heating Refrigerating and Air-conditioning Engineers (2019)

9. SCALE 2004. Baseline report on research needs in the framework of the European Environment and Health Strategy (COM 2003)338 final. http://www.brusselsconfer ence.org/Download/Baseline_report_TWG_Research_ Needs_fin.pdf

10. Nigeria, Federal Environmental Protection Agency. Guidelines and standards for environmental pollution control in Nigeria. Federal Environmental Protection Agency (FEPA), 1991 
11. C.P. Choo, J. Jalaludin, T.R. Hamedon, N.M. Adam, Preschools' indoor air quality and respiratory health symptoms among pre-schoolers in Selangor, Proc. Environ. Sci. 30, 303-308 (2015)

12. M.G. Apte, W.J. Fisk, J.M. Daisey, Indoor carbon dioxide concentrations and SBS in office workers, in Proceedings of Healthy Buildings 2000 (Vol. 1, p. 133)

13. O. Oguntoke, B.O. Opeolu, N. Babatunde, Indoor air pollution and health risks among rural dwellers in Odeda area, South-Western Nigeria, Ethiop. J. Environ. Stud. Manag. 3 (2010)

14. M.M. Pitt, M.R. Rosenzweig, M.N. Hassan, Sharing the burden of disease: gender, the household division of labour and the health effects of indoor air pollution in Bangladesh and India, in Stanford Institute for Theoretical Economics Summer Workshop 2006 Jun (Vol. 202)

15. R.R. Akpofure, An assessment of indoor air quality in selected households in squatter settlement Warri, Nigeria, Adv. Life Sci. 5, 1-1 (2015)

16. E. Emagbetere, J. Odia, B.U. Oreko, Assessment of household energy utilized for cooking in Ikeja, Lagos State, Nigeria, Niger. J. Technol. 35, 796-804 (2016)

17. A.E. Ite, C.O. Ogunkunle, C.O. Obadimu, E.R. Asuaiko, U.J. Ibok, Particulate Matter and Staff Exposure in an AirConditioned Office in Akwa Ibom State University-Nigeria, J. Atmos. Pollut. 5, 24-32 (2017)

18. N.H. Wong, W.L. Jan, Total building performance evaluation of academic institution in Singapore, Build. Environ. 38, 161-176 (2003)

19. E. Abt, H.H. Suh, P. Catalano, P. Koutrakis, Relative contribution of outdoor and indoor particle sources to indoor concentrations, Environ. Sci. Technol. 34, 3579-3587 (2000)

20. D.Y. Leung, Outdoor-indoor air pollution in urban environment: challenges and opportunity, Front. Environ. Sci. 2, 69 (2015)

21. F. Allard, in Natural ventilation in buildings: a design handbook, edited by F. Allard (James \& James, London, 1998)

22. American Society of Heating, Refrigerating, Air-Conditioning Engineers, ASHRAE Standard: Ventilation for Acceptable Indoor Air Quality. American Society of Heating, Refrigerating and Air-Conditioning Engineers, Incorporated (1989)

23. S. Petty, Summary of Ashrae's position on carbon dioxide $\left(\mathrm{CO}_{2}\right)$ levels in spaces $(2014)$

24. M. Schell, D. Int-Hout, Demand control ventilation using $\mathrm{CO}_{2}$, ASHRAE J. 43, 18-29 (2001)

25. American Society of Heating, Refrigerating, Air-Conditioning Engineers, American National Standards Institute. Ventilation for acceptable indoor air quality. American Society of Heating, Refrigerating and Air-Conditioning Engineers, 2002
26. E. Gratia, I. Bruyere, A. De Herde, How to use natural ventilation to cool narrow office buildings, Build. Environ. 39, 1157-1170 (2004)

27. P. Karava, T. Stathopoulos, A.K. Athienitis, Airflow assessment in cross-ventilated buildings with operable façade elements, Build. Environ. 46, 266-279 (2011)

28. S. Holmberg, Q. Chen, Air flow and particle control with different ventilation systems in a classroom, Indoor Air 13, 200-204 (2003)

29. T. Ekwevugbe, N. Brown, D. Fan, Using indoor climatic measurements for occupancy monitoring, in Proceedings of 4th West Africa, Built Environment Research (WABER) Conference, Abuja, Nigeria (2012) pp. 507-520

30. E.A. Olanipekun, Examination of thermal comfort in a naturally ventilated hostel using PMV-PPD model and field survey, Am. J. Eng. Res. 3, 63-78 (2014)

31. ANSI/ASHRAE 55-2017 Thermal Environmental Conditions for Human Occupancy. American Society of Heating, Refrigerating and Air Conditioning Engineers, Atlanta, GA, USA (2017)

32. J.L. Nguyen, D.W. Dockery, Daily indoor-to-outdoor temperature and humidity relationships: a sample across seasons and diverse climatic regions, Int. J. Biometeorol. 60, 221-229 (2016)

33. G. Smedje, C.K. Norbåd, C. Edling, Subjective indoor air quality in schools in relation to exposure, Indoor Air 7, 143-150 (1997)

34. I.A. Sakellaris, D.E. Saraga, C. Mandin, C. Roda, S. Fossati, Y. De Kluizenaar, P. Carrer, S. Dimitroulopoulou, V.G. Mihucz, T. Szigeti, O. Hänninen, Perceived indoor environment and occupants' comfort in European "modern" office buildings: The OFFICAIR study, Int. J. Environ. Res. Public Health 13, 444 (2016)

35. R. Prill, Why measure carbon dioxide inside buildings. Published by Washington State University Extension Energy Program WSUEEP07 (2000)

36. U. Haverinen, R.J. Shaughnessy, E.C. Cole, O. Toyinbo, D.J. Moschandreas, An assessment of indoor environmental quality in schools and its association with health and performance, Build. Environ. 93, 35-40 (2015)

37. S. Bae, A. Asojo, D. Guerin, C. Martin, A post-occupancy evaluation of the impact of indoor environmental quality on health and well-being in office buildings, J. Organ. Psychol. 17, 25-36 (2017)

38. P. Wolkoff, Indoor air humidity, air quality, and health - an overview, Int. J. Hygiene Environ. Health 221, 376-390 (2018)

39. B. Berglund, B. Brunekreef, H. Knoppel, T. Lindvall, M. Maroni, L. Mølhave, P. Skov, Effects of indoor air pollution on human health, Indoor Air 2, 2-5 (1992)

Cite this article as: B.A. Orola: Seasonal variations in indoor air quality parameters and occupants self-reported physical health within a warm humid climatic environment. Sust. Build. 5, 2 (2020). 


\section{Appendix}

Physical characteristics of the different spatial design layout types, measured indoor air quality data (for dry and wet season in that order), and outdoor climatic data.

Room layout type 1 (3-bedded room for male and female) Floor area $=21 \mathrm{~m}^{2}$

External wall area $=16.83 \mathrm{~m}^{2}$

Window area $=4.32 \mathrm{~m}^{2}$

Window to floor area ratio $=0.207$

Window to external wall area ratio $=0.256$
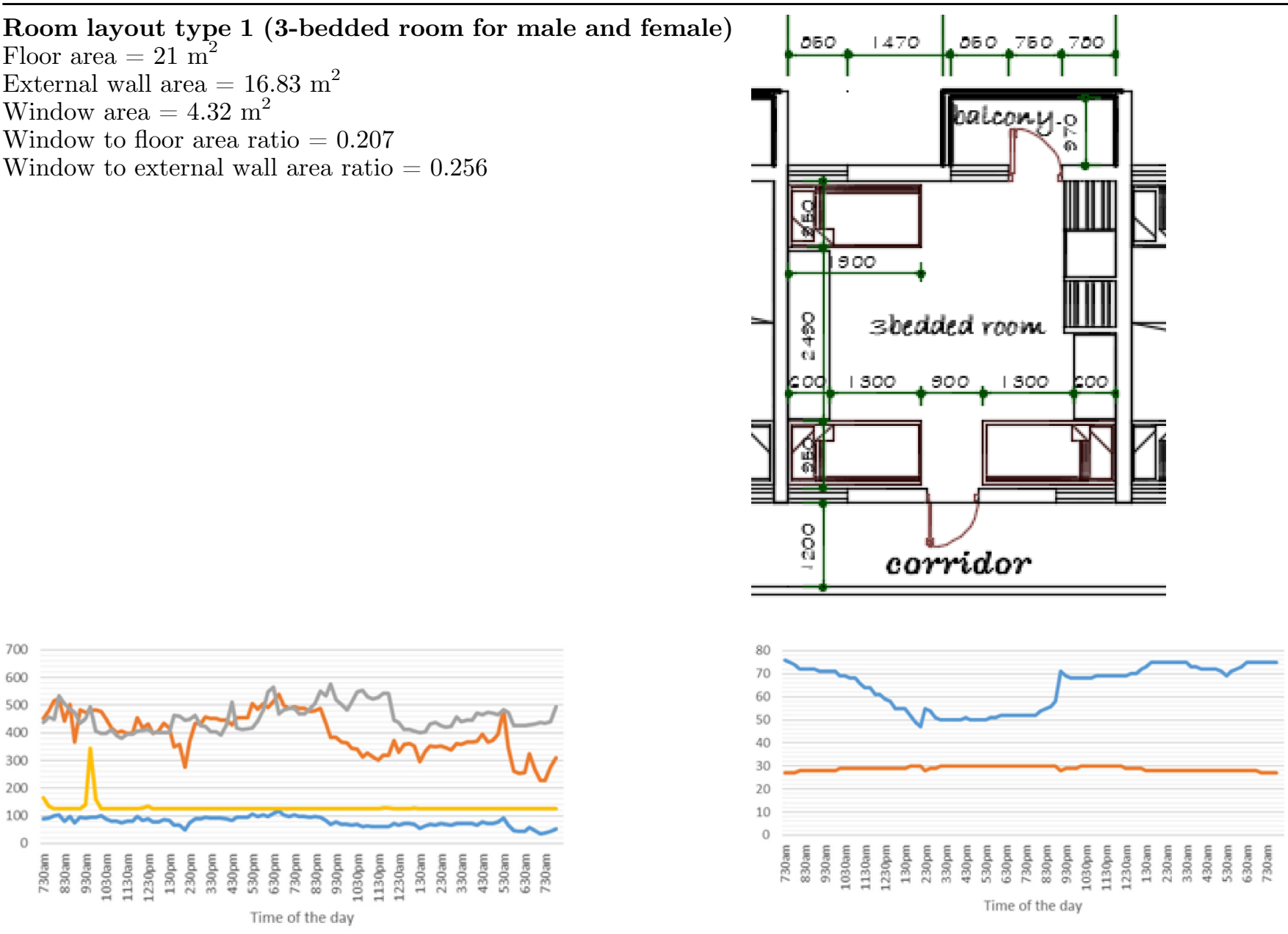

$\longrightarrow \mathrm{PM} 2.5\left(\mu \mathrm{g} / \mathrm{m}^{2}\right)-\mathrm{PM} 10\left(\mu \mathrm{g} / \mathrm{m}^{3}\right)-\mathrm{CO}_{2}(\mathrm{ppm})-\mathrm{TVOC}(\mathrm{ppb})$

- Relative Humidity (\%) - Air temperature $\left({ }^{\circ} \mathrm{C}\right)$
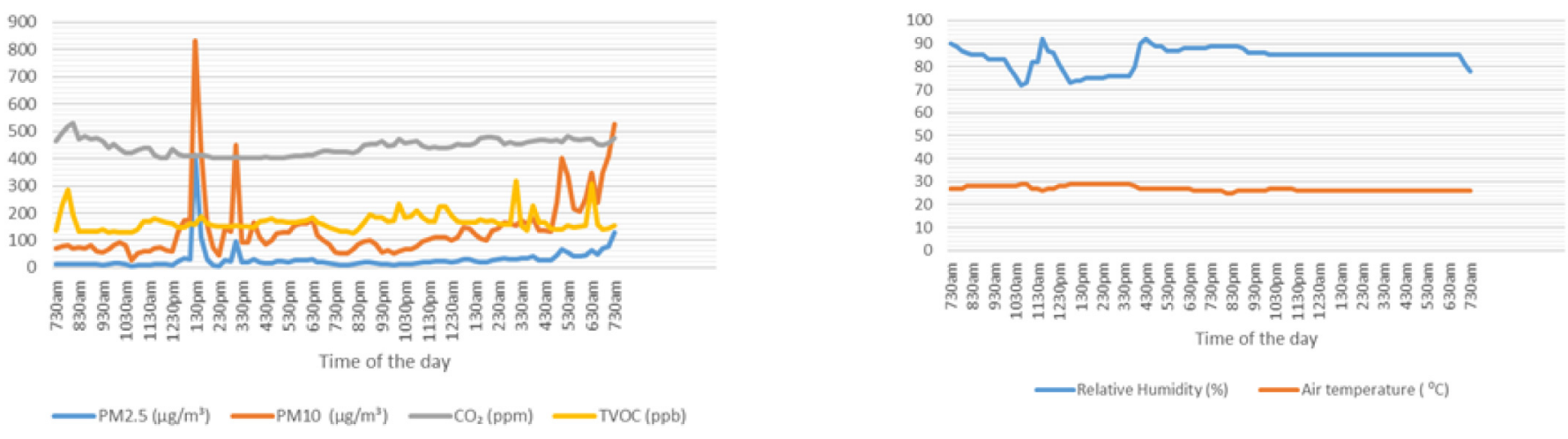
Room layout type 2 (1-bedded room for male and female) Floor area $=10 \mathrm{~m}^{2}$

External wall area $=5.82 \mathrm{~m}^{2}$

Window area $=1.8 \mathrm{~m}^{2}$

Window to floor area ratio $=0.18$

Window to external wall area ratio $=0.309$
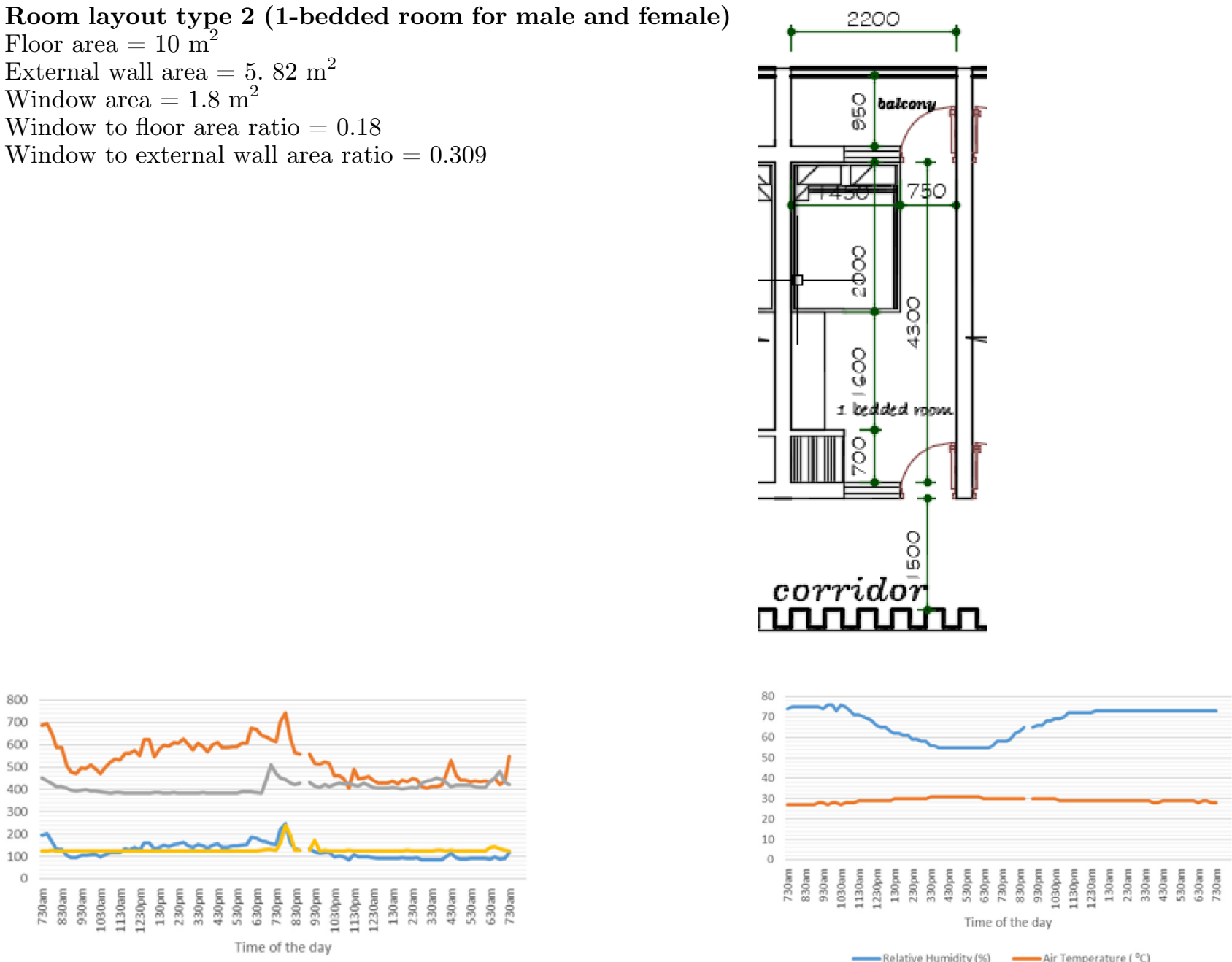

$\longrightarrow$ PM2.5 $\left(\mu \mathrm{g} / \mathrm{m}^{3}\right)-\mathrm{PM} 10\left(\mu \mathrm{g} / \mathrm{m}^{3}\right)-\mathrm{CO}_{2}(\mathrm{ppm})-\mathrm{TVOC}(\mathrm{ppb})$
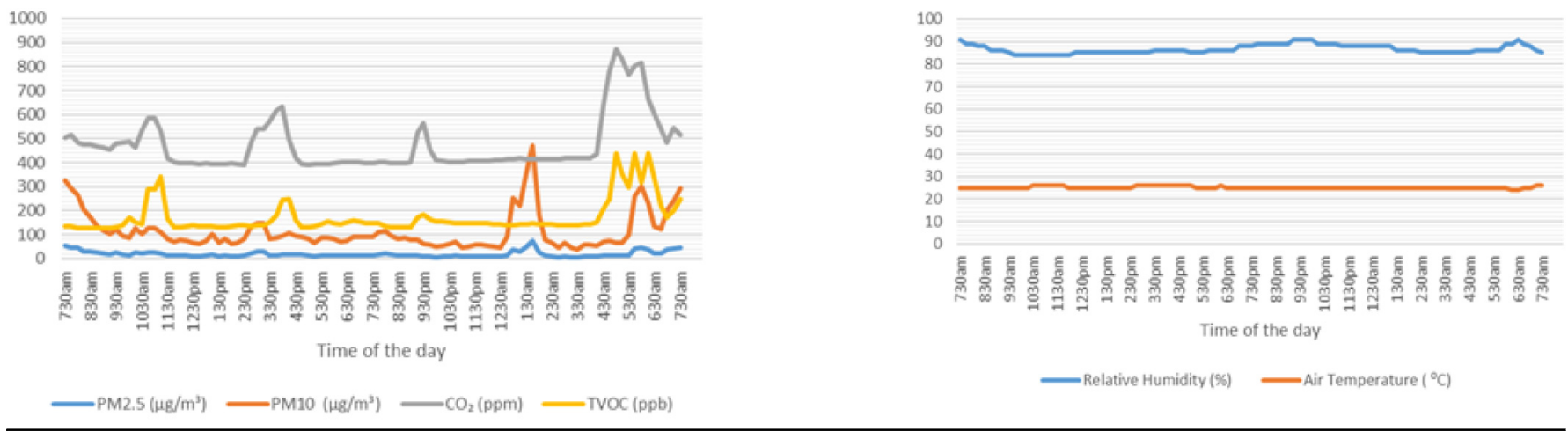
Room layout type 3 (8-bedded room for male)

Floor area $=24 \mathrm{~m}^{2}$

External wall area $=25.08 \mathrm{~m}^{2}$

Window area $=1.8 \mathrm{~m}^{2}$

Window to floor area ratio $=0.078$

Window to external wall area ratio $=0.072$

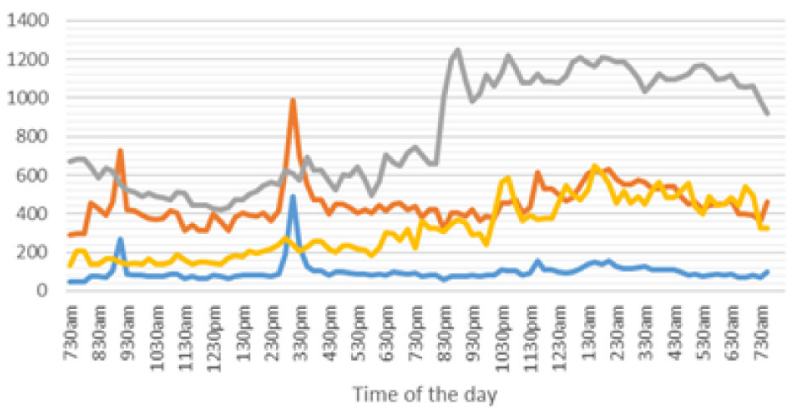

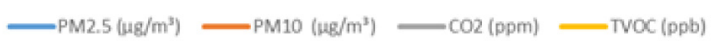

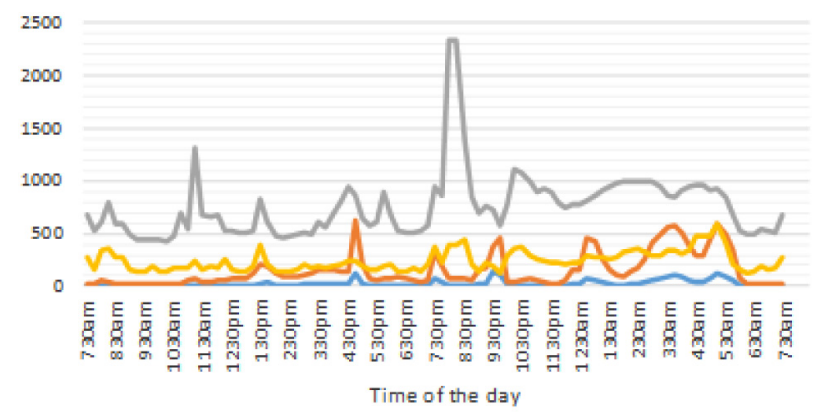

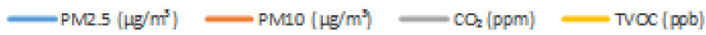
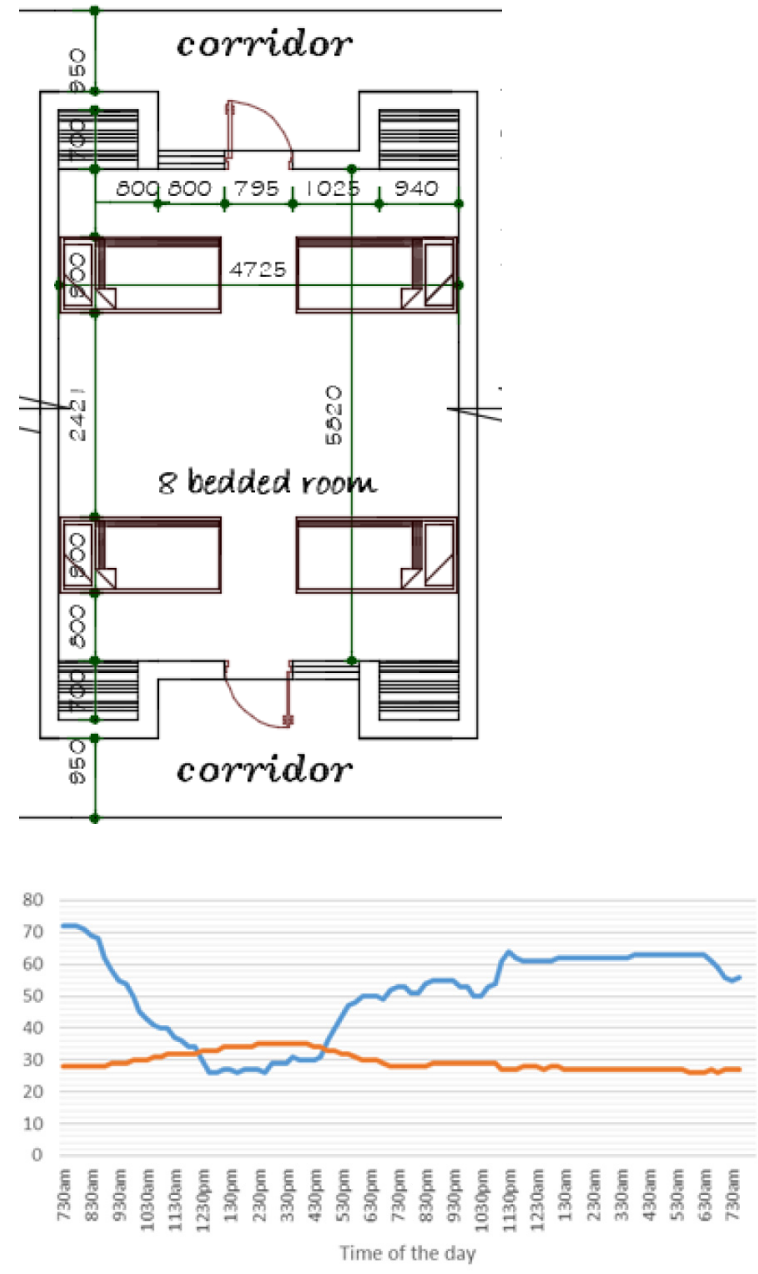

- Relative Humidity (\%) — Air Temperature $\left({ }^{\circ} \mathrm{C}\right)$

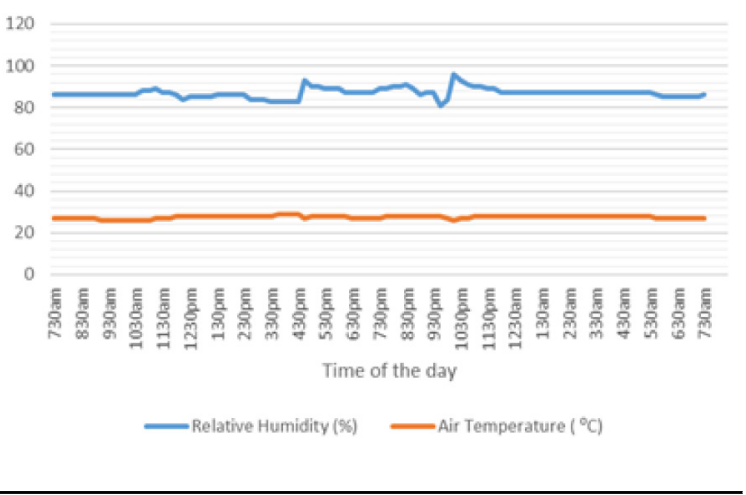


Room layout type 4 (8-bedded room for female) Floor area $=24 \mathrm{~m}^{2}$

External wall area $=25.08 \mathrm{~m}^{2}$

Window area $=1.8 \mathrm{~m}^{2}$

Window to floor area ratio $=0.078$

Window to external wall area ratio $=0.072$

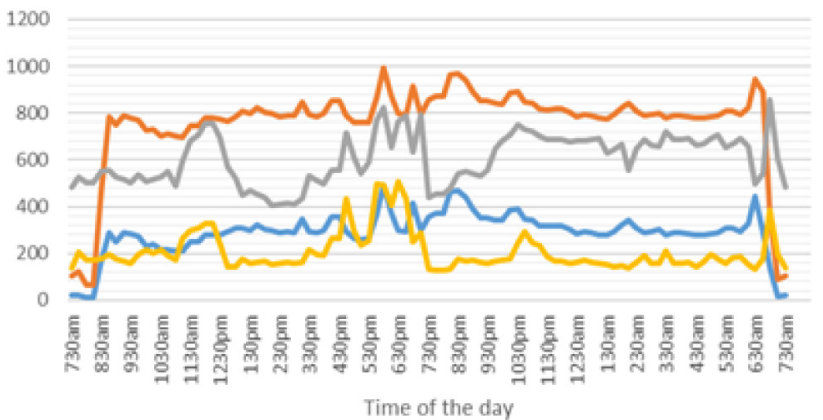

$\longrightarrow \mathrm{PM} 2.5\left(\mathrm{\mu g} / \mathrm{m}^{3}\right)-\mathrm{PM} 10\left(\mathrm{\mu g} / \mathrm{m}^{3}\right)-\mathrm{CO}(\mathrm{ppm})-\mathrm{TVOC}(\mathrm{ppb})$
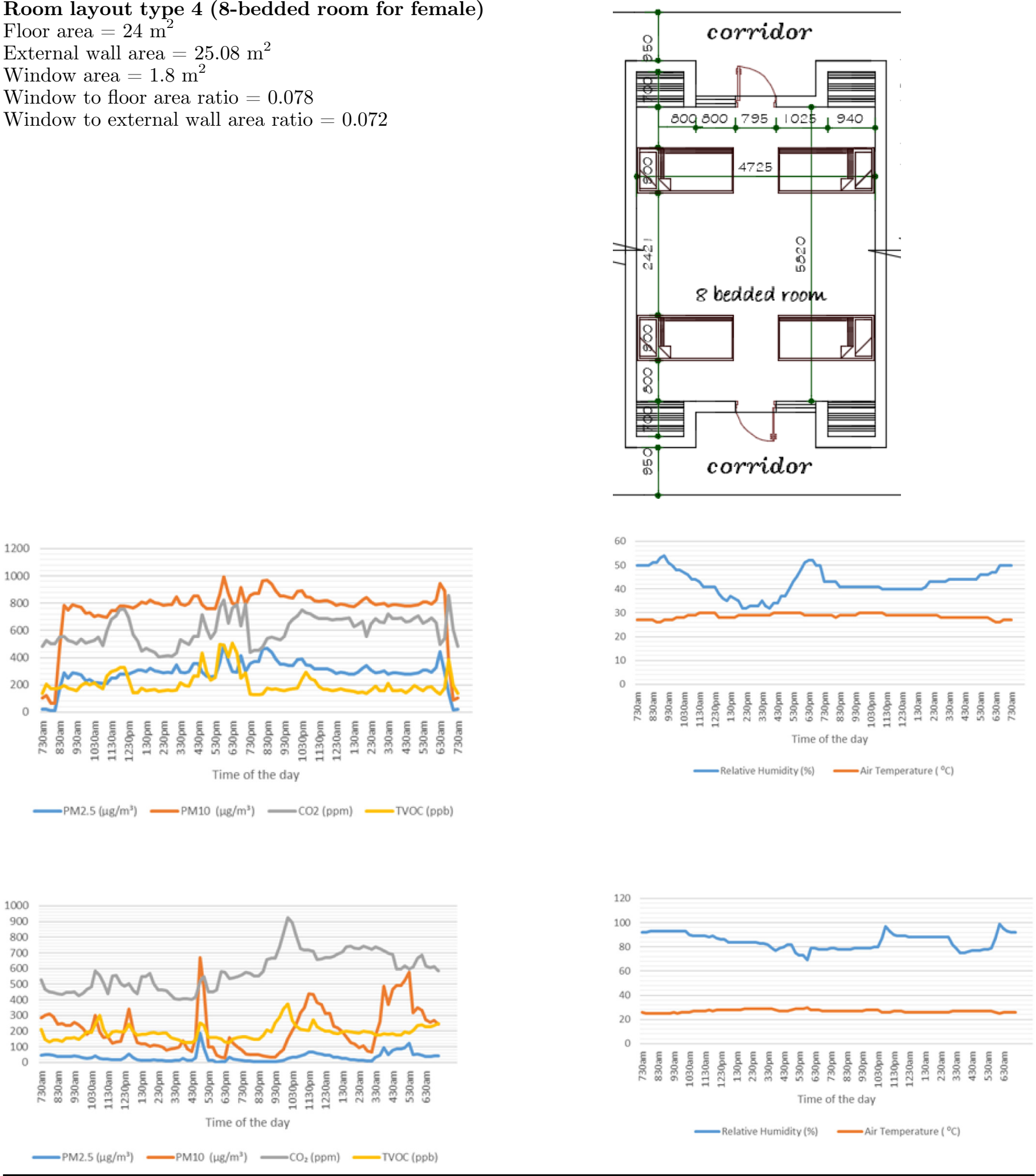

- Relative Humidity (\%) - Air Temperature $\left({ }^{\circ} \mathrm{C}\right)$ 
Room layout type 5 (4-bedded room for male)

Floor area $=18 \mathrm{~m}^{2}$

External wall area $=18.35 \mathrm{~m}^{2}$

Window area $=6.09 \mathrm{~m}^{2}$

Window to floor area ratio $=0.35$

Window to external wall area ratio $=0.33$
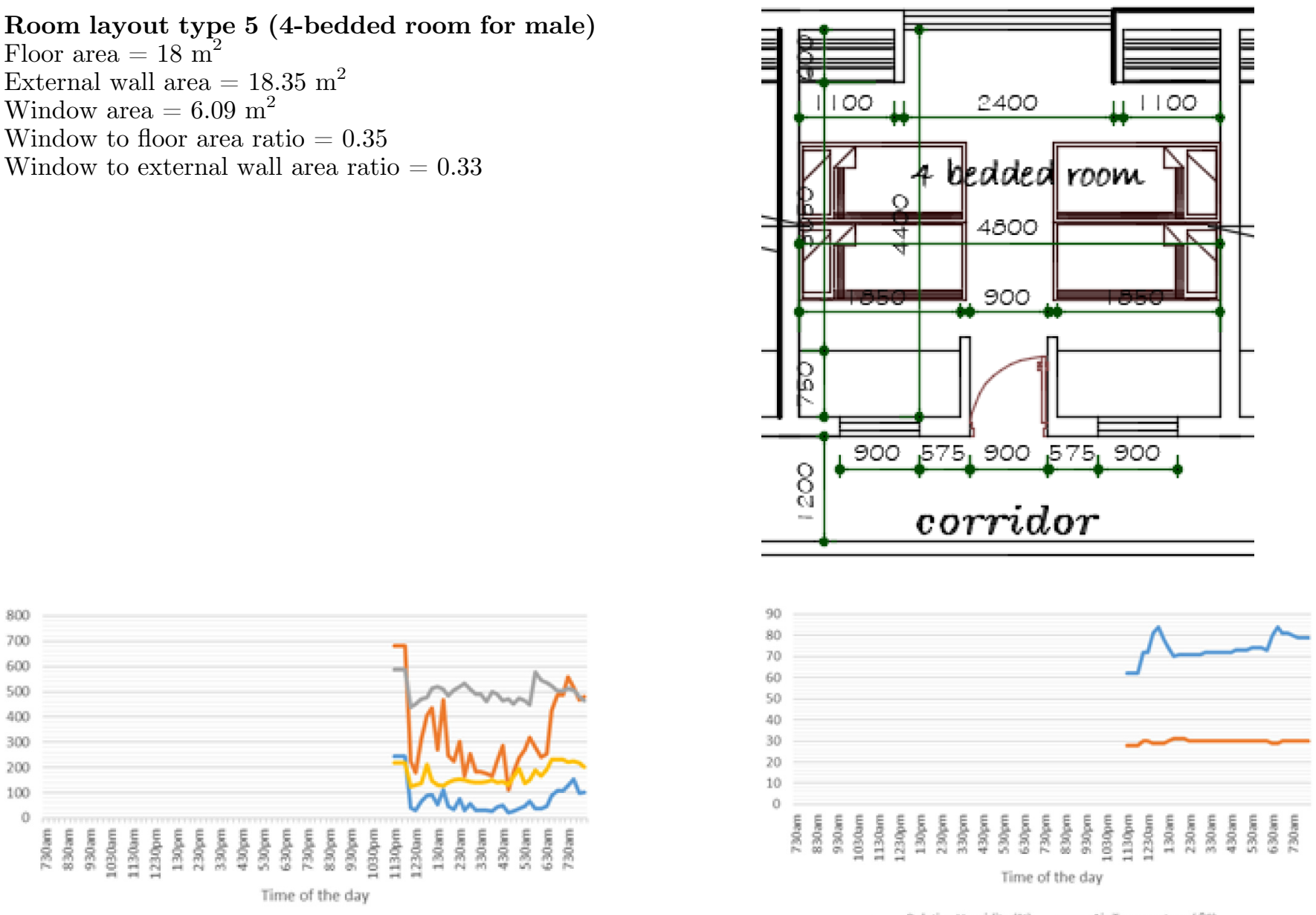

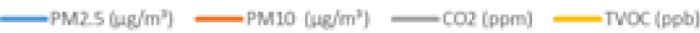
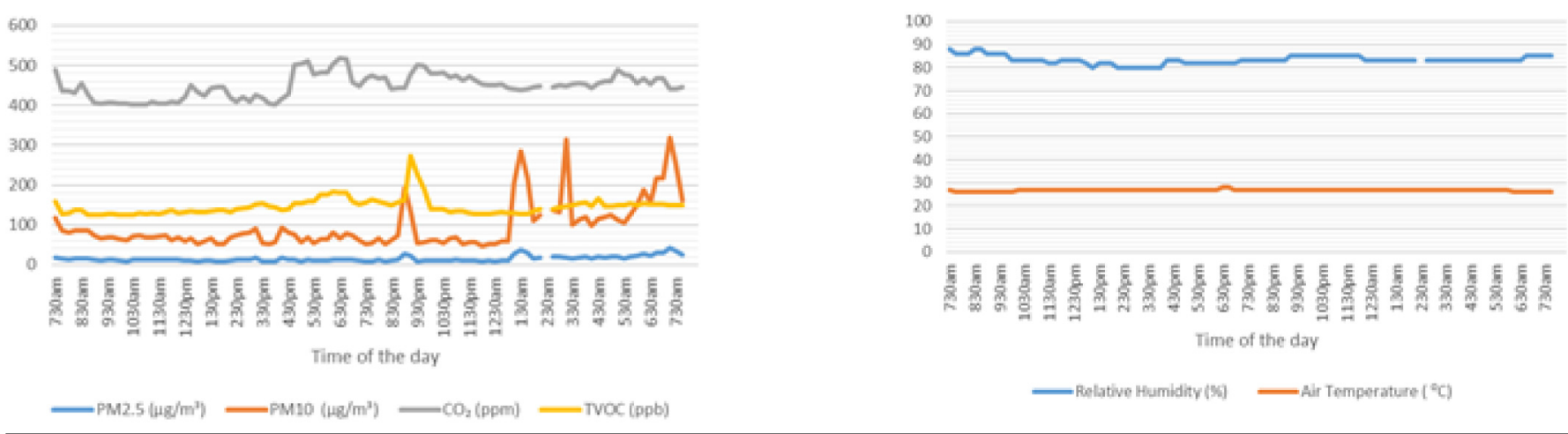
Room layout type 6 (4-bedded room for male)

Floor area $=19 \mathrm{~m}^{2}$

External wall area $=13.68 \mathrm{~m}^{2}$

Window area $=9.84 \mathrm{~m}^{2}$

Window to floor area ratio $=0.52$

Window to external wall area ratio $=0.72$

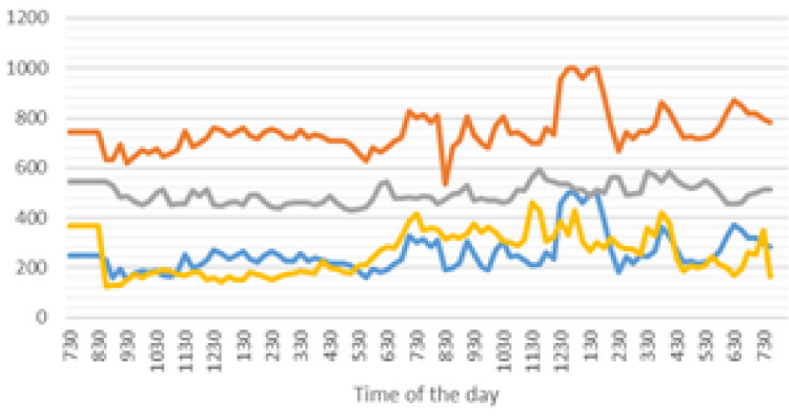

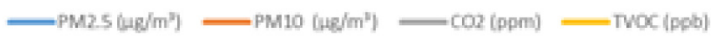

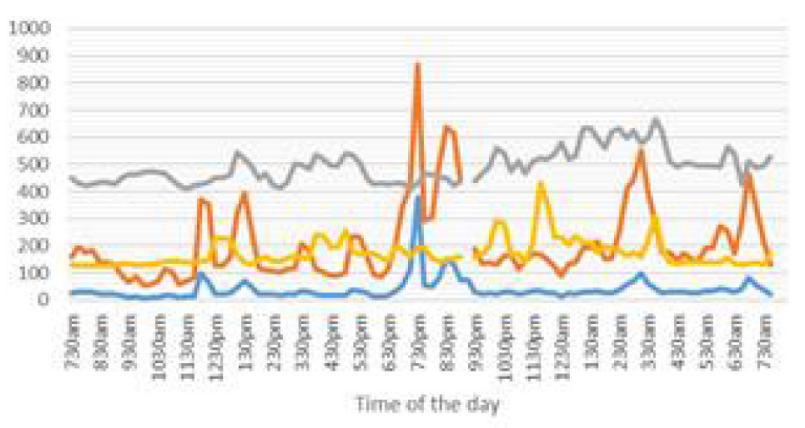

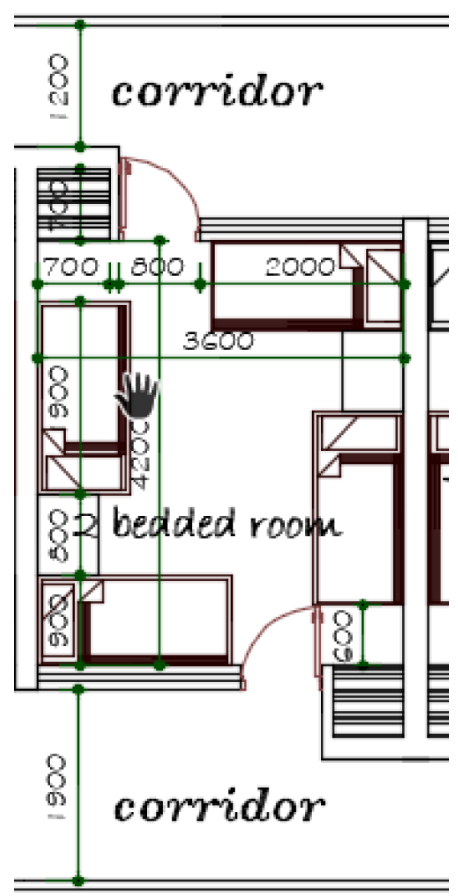

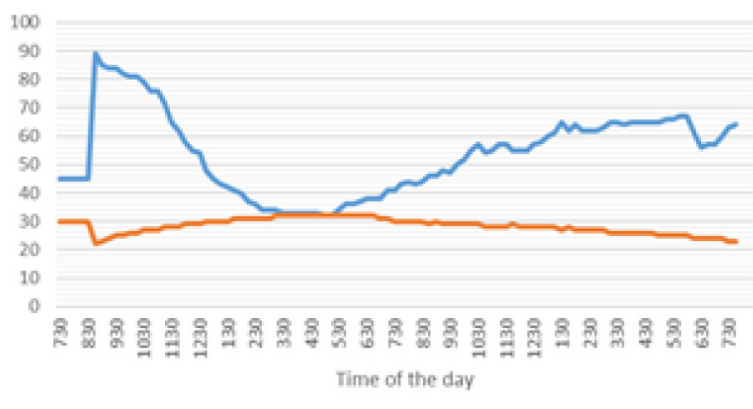

- Bellative Humidity (SO) - Air Temperature $\left[{ }^{\circ} \mathrm{C}\right.$

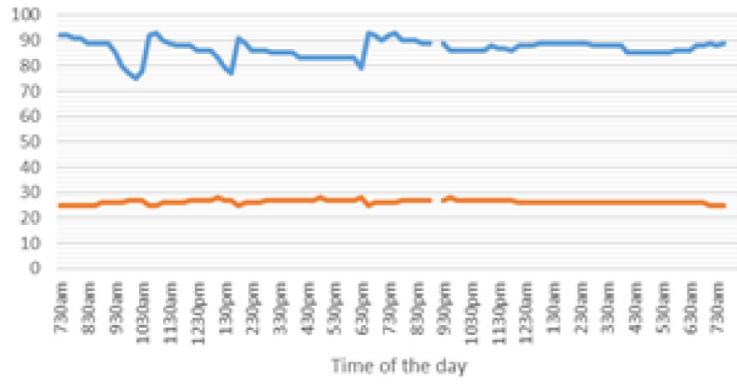

- Relative Humidity(w) - Air Temperature ("C) 
Room layout type 7 (3-bedded room for male)

Floor area $=18 \mathrm{~m}^{2}$

External wall area $=9.63 \mathrm{~m}^{2}$

Window area $=3.6 \mathrm{~m}^{2}$

Window to floor area ratio $=0.2$

Window to external wall area ratio $=0.3738$

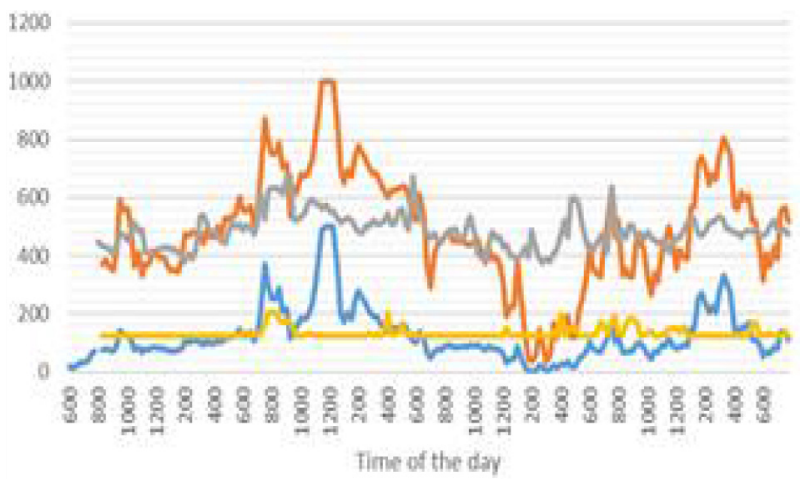

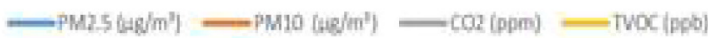

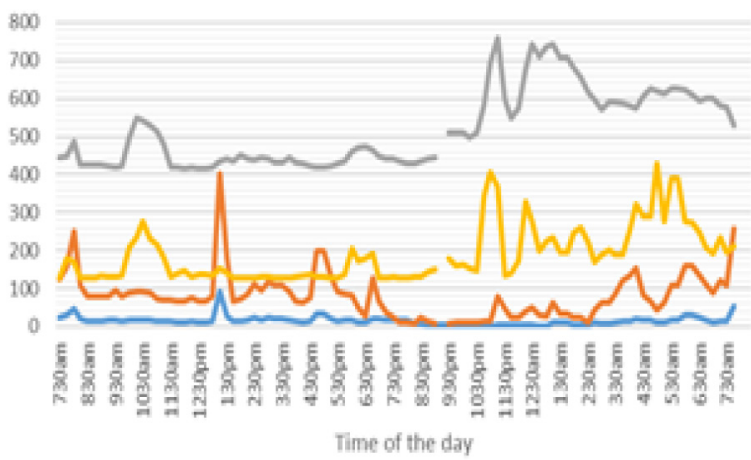

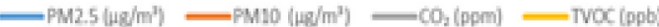
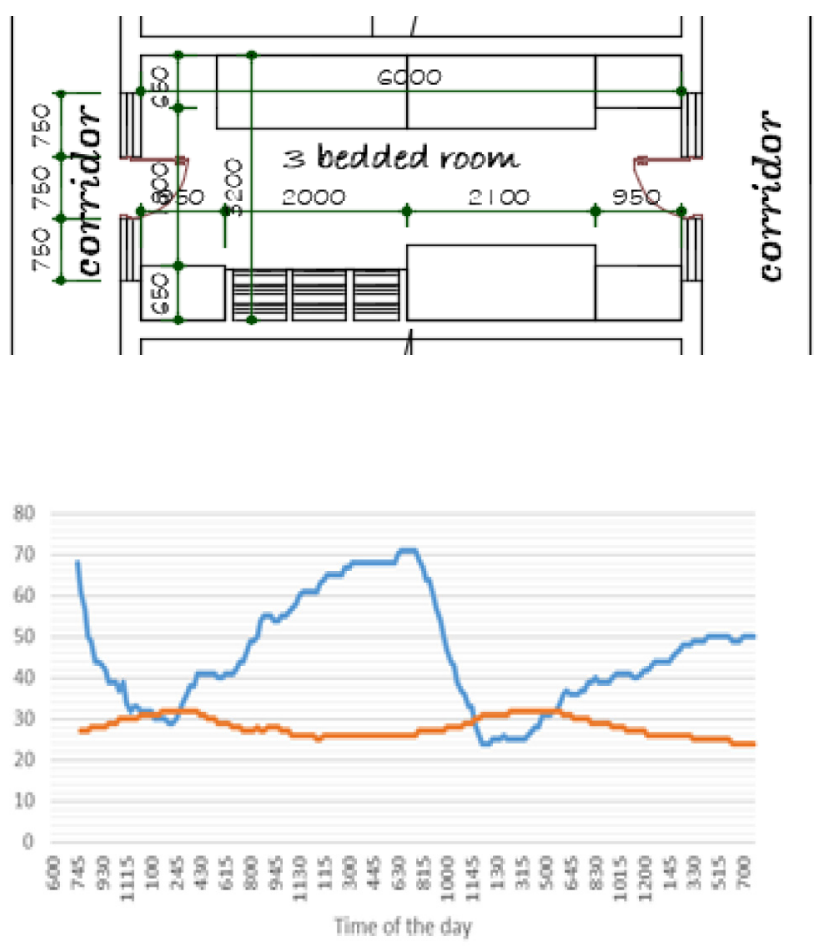

- Bolative Humidity (x) -Air Temperature ("C)

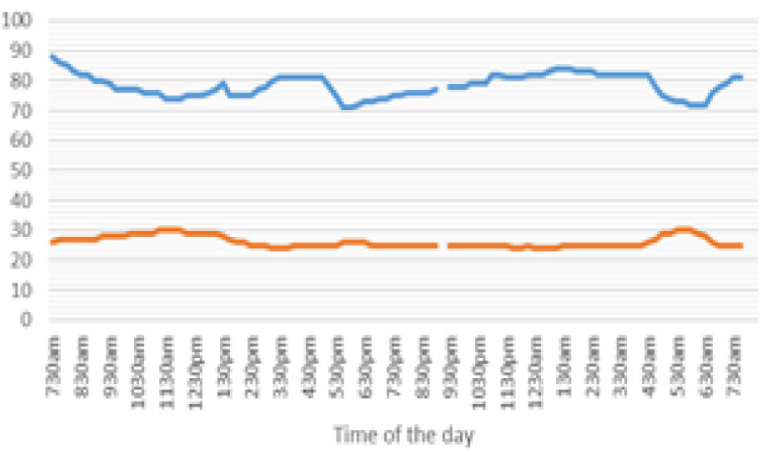

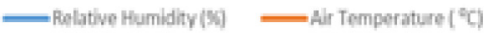


Room layout type 8 (2-bedded room for male)

Floor area $=22 \mathrm{~m}^{2}$

External wall area $=7.7 \mathrm{~m}^{2}$

Window area $=9.31 \mathrm{~m}^{2}$

Window to floor area ratio $=0.43$

Window to external wall area ratio $=1.21$

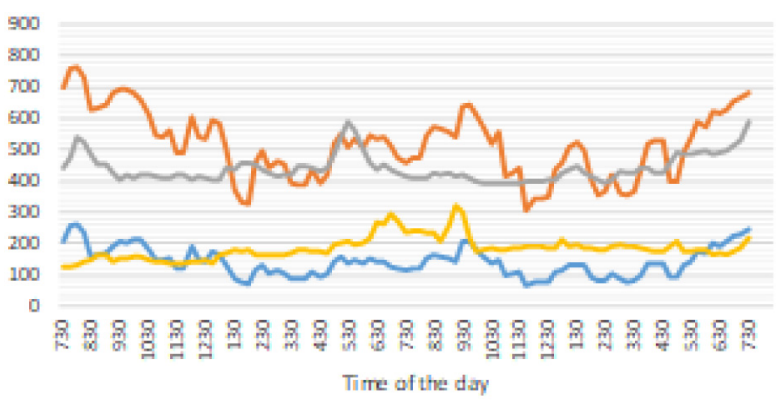

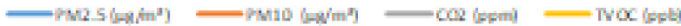

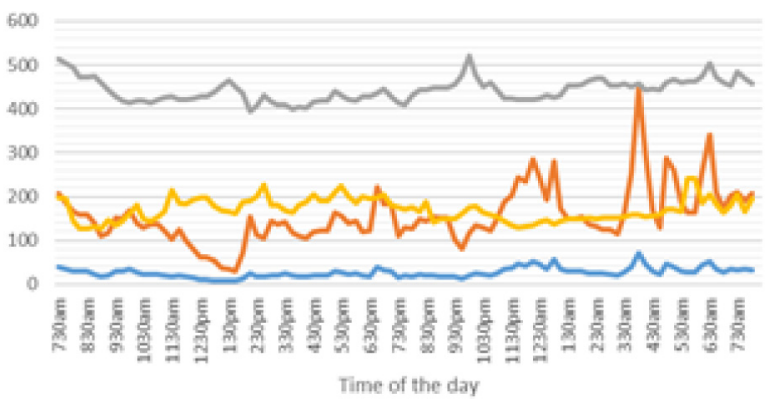

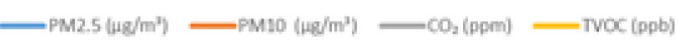
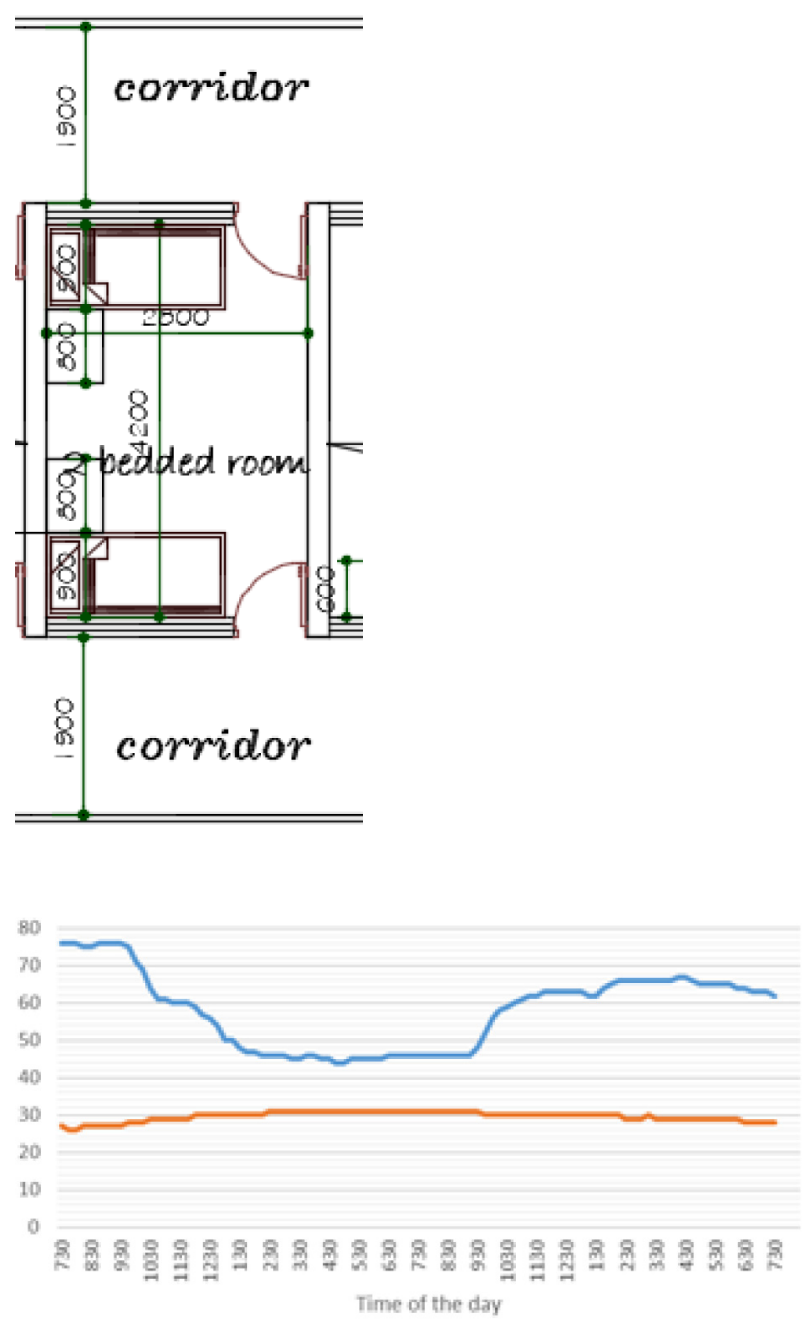

- Holative Humidity (50] _ Air Temperature ("C)

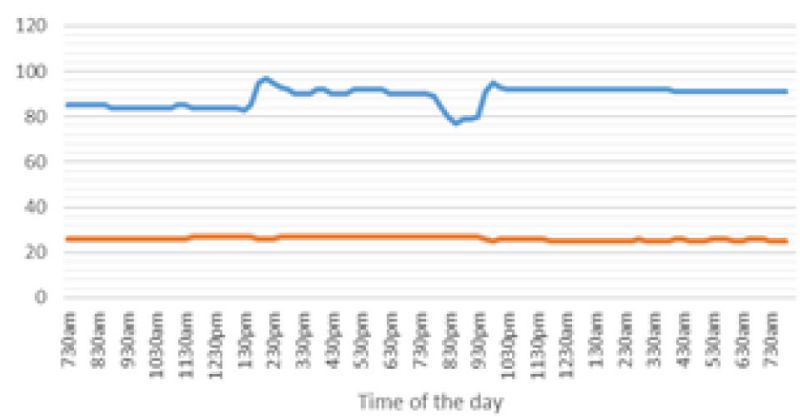

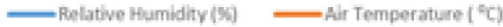


Room layout type 9 (4-bedded room for female) Floor area $=20.69 \mathrm{~m}^{2}$

External wall area $=17.67 \mathrm{~m}^{2}$

Window area $=3.28 \mathrm{~m}^{2}$

Window to floor area ratio $=0.16$

Window to external wall area ratio $=0.19$
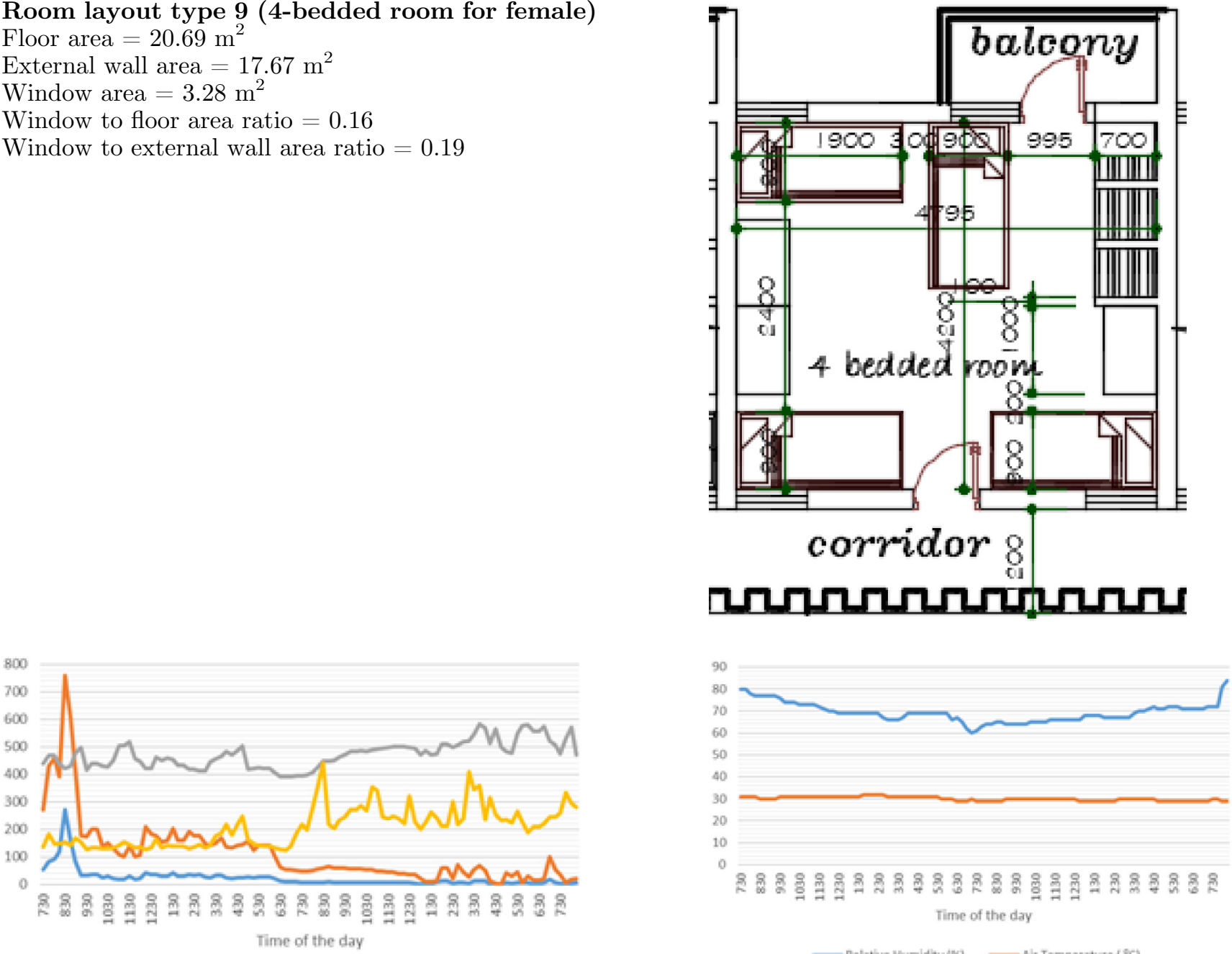

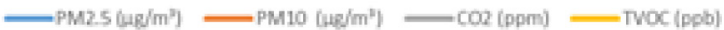
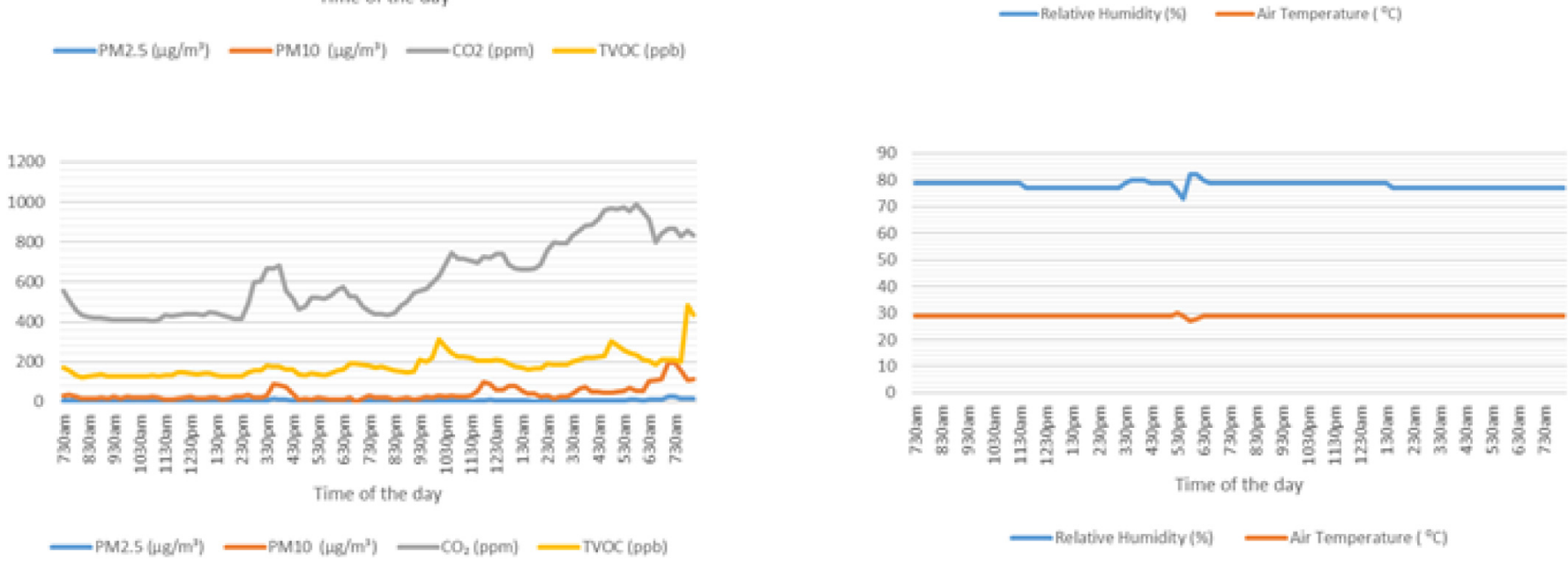

Source: Authors fieldwork, (2018). 


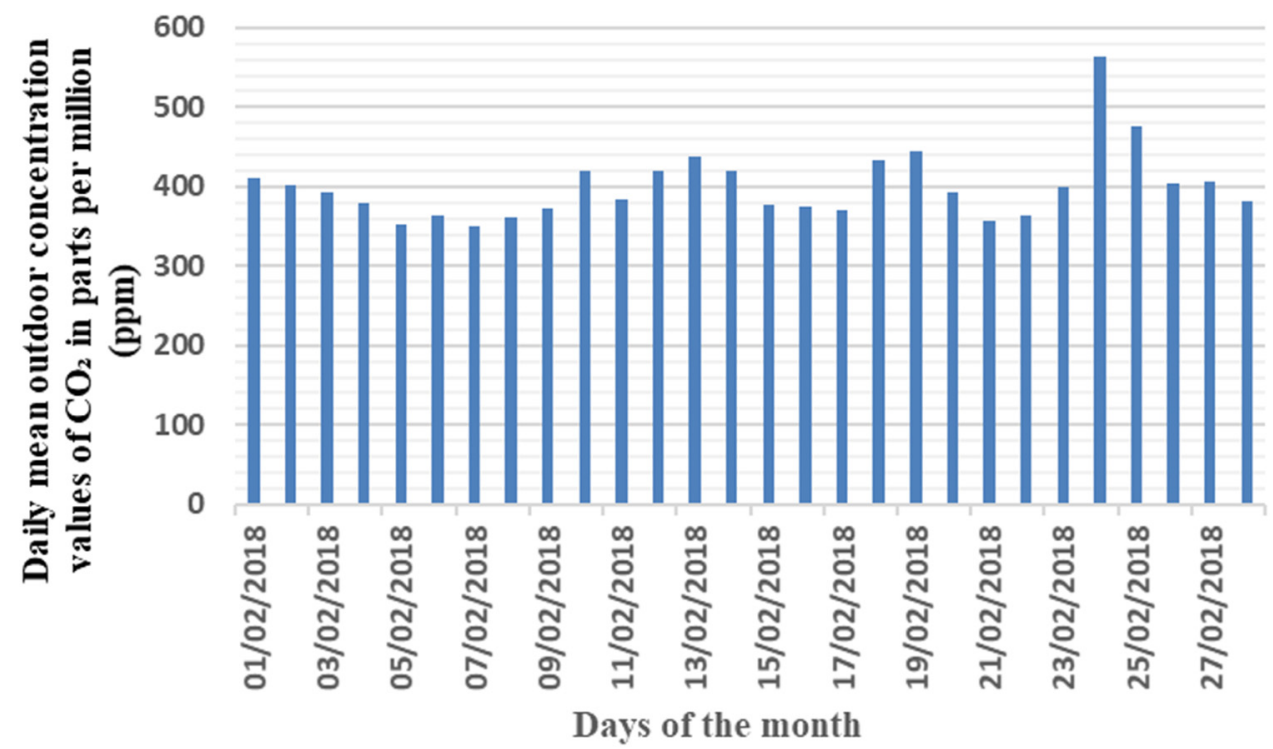

Outdoor Carbon Dioxide $\left(\mathrm{CO}_{2}\right)$ concentration values during February, 2018.

Source: Nigeria Micrometeorological Experiment (NIMEX) Obafemi Awolowo University Ile-Ife (2018).

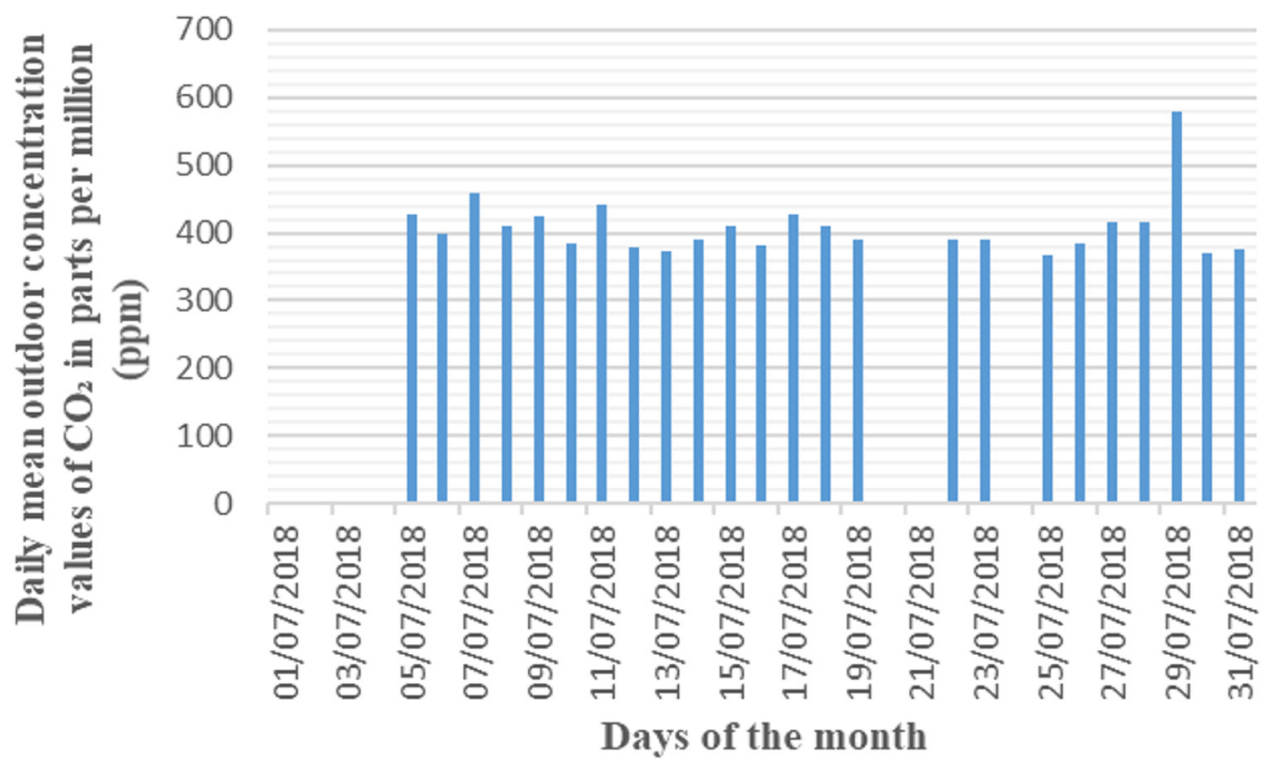

Outdoor Carbon Dioxide $\left(\mathrm{CO}_{2}\right)$ concentration values during July, 2018.

Source: Nigeria Micrometeorological Experiment (NIMEX) Obafemi Awolowo University Ile-Ife (2018). 


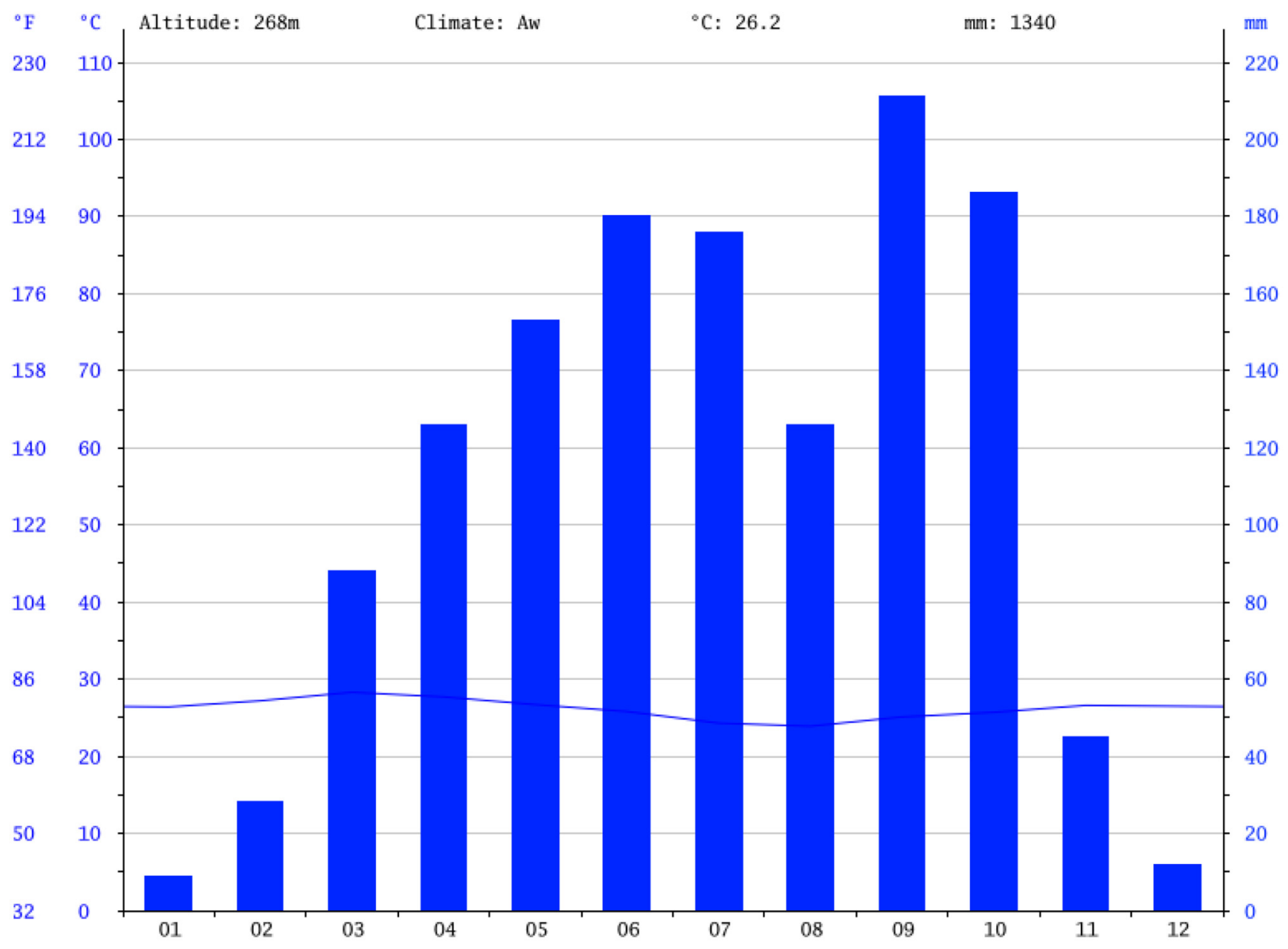

Fig. A1. Weather chart of Ile-Ife for a typical year. Source: CLIMATE-DATA.ORG. 


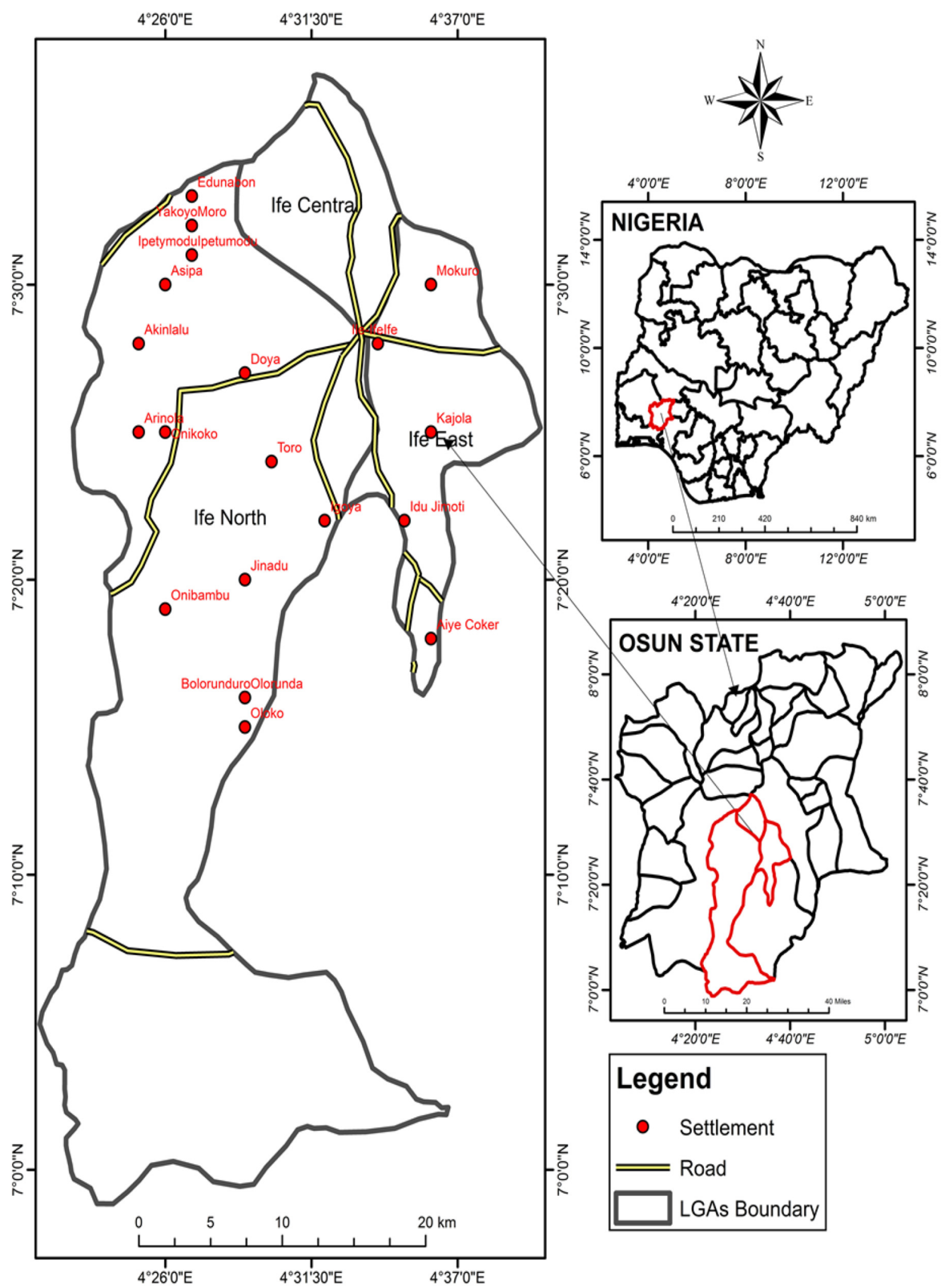

Fig. A2. Map of Ile-Ife with map of Osun state and Nigeria at the background. Source: Google map 2018. 


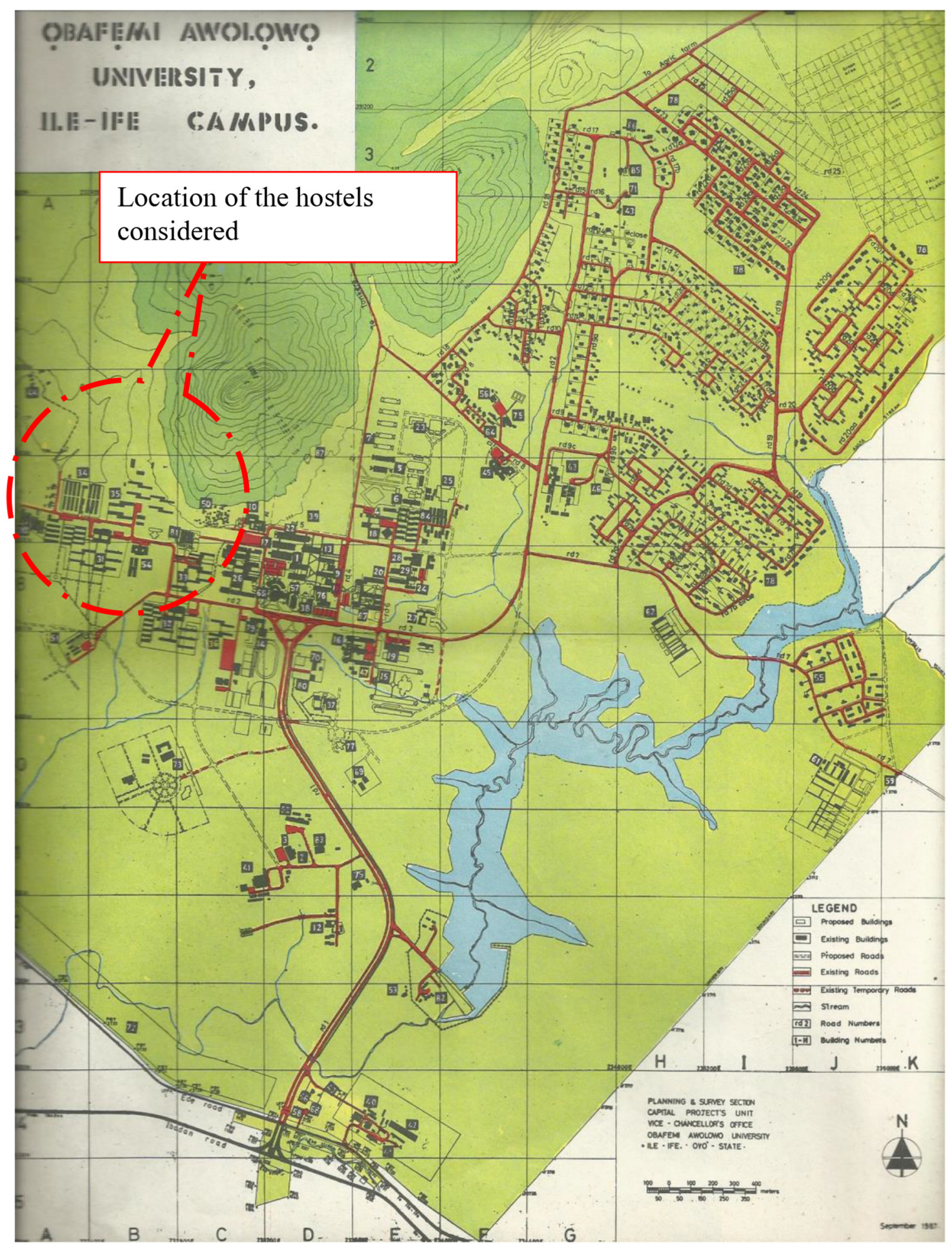

Plate A1. Obafemi Awolowo University Campus Map. Source: Physical Planning \& Development Unit, Obafemi Awolowo University, Ile Ife, 2018. 


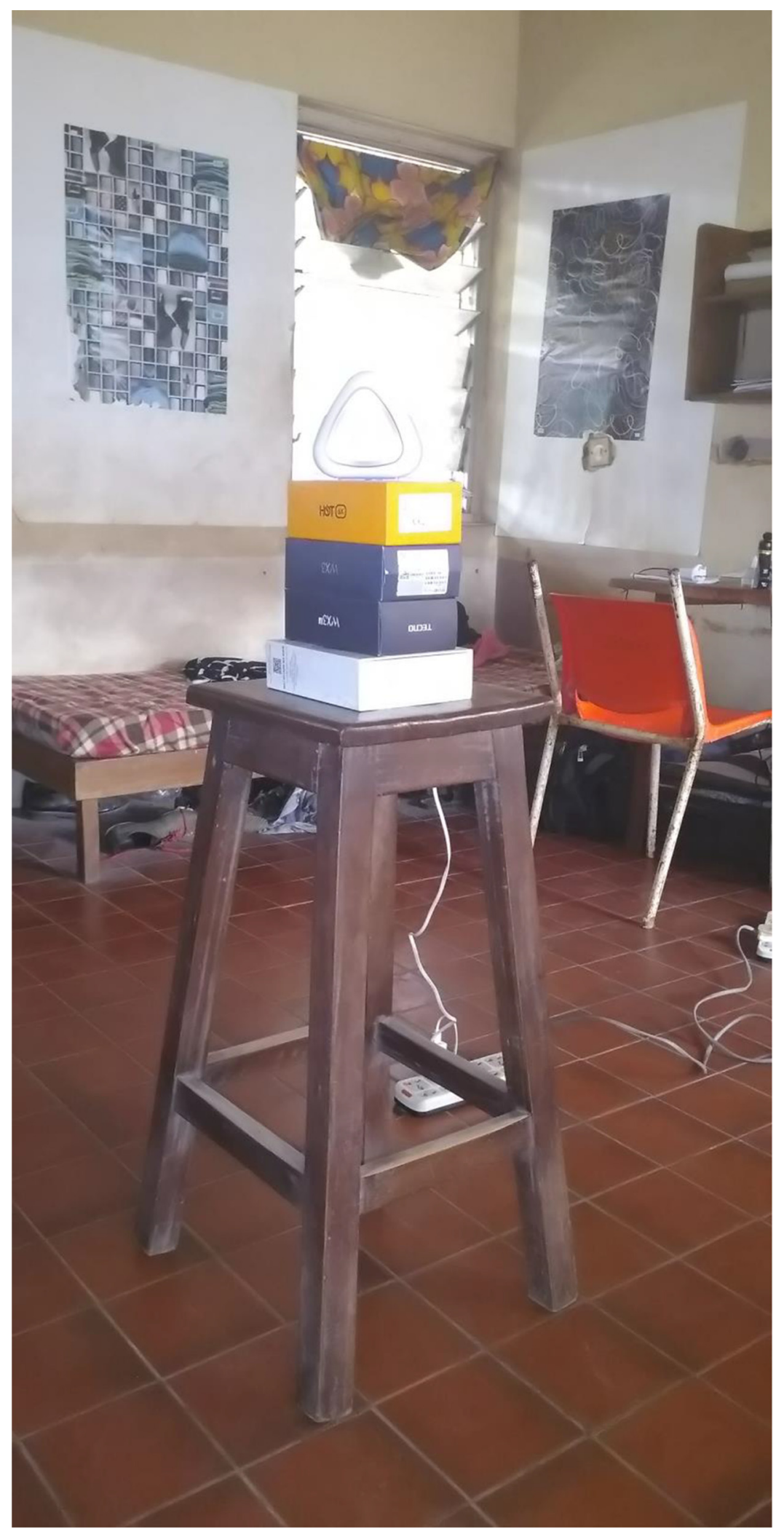

Plate A2. Setting of the data logger (Air Mentor Pro) in a typical room. Source: Authors field work, 2018. 
Questionnaire on indoor air quality and self-reported physical health in student hostels (Sample)

1. Name of Hostel:

2. Respondent's weight:

3. Respondent's height:

\section{Respondent's complexion:}

Dear respondent,

This questionnaire is designed to elicit responses on issues relating to indoor air quality in spaces within student hostel buildings in Obafemi Awolowo University, Nigeria. It is mainly an instrument for gathering data for an on-going research on the relationships among the quality of the indoor environment and the occupants' health. All information provided will be treated with confidentiality and used only for academic purposes.

(Please tick the appropriate box)

\section{Section A (General information about the room and occupants behavior)}

1 . How many people sleep in your room regularly?

\begin{tabular}{|l|l|l|l|l|l|l|l|l|}
\hline 1 & 2 & 3 & 4 & 5 & 6 & 7 & 8 & Others specify \\
\hline & & & & & & & & \\
\hline
\end{tabular}

2. What activities are mainly carried out inside the room? (You can tick more than one box).

\begin{tabular}{|l|l|}
\hline Sleeping & \\
\hline Reading & \\
\hline Eating & \\
\hline Cooking & \\
\hline Laundry & \\
\hline Smoking & \\
\hline Others specify & \\
\hline
\end{tabular}

3. What is the status of the mosquito net or fly-screen in the room?

\begin{tabular}{|l|l|l|l|}
\hline $100 \%$ in order & Fairly in order & In total disrepair & No mosquito net at all \\
\hline & & & \\
\hline
\end{tabular}

4. Do the windows in the room have curtains?

\begin{tabular}{|l|l|}
\hline Yes & No \\
\hline & \\
\hline
\end{tabular}

5. What type of artificial ventilation system(s) is/are available in the room?

\begin{tabular}{|l|l|l|l|l|l|}
\hline None & Standing/ Table fan & Ceiling fan & Window unit A/C & Split unit A/C & (Big) Package unit A/C \\
\hline & & & & & \\
\hline
\end{tabular}

6. What percentage of the window area do you open most times?

\begin{tabular}{|l|l|l|l|l|}
\hline Small part & Almost half & Half & More than half & All \\
\hline & & & & \\
\hline
\end{tabular}


Section B (Information about the room users)

1. What is your status on campus?

\begin{tabular}{|l|l|l|l|l|}
\hline Part-time student & Undergraduate & Post-graduate & Diploma student & Others specify \\
\hline & & & & \\
\hline
\end{tabular}

2. What is your gender?

\begin{tabular}{|l|l|}
\hline Male & Female \\
\hline & \\
\hline
\end{tabular}

3. What is your age-group?

\begin{tabular}{|l|l|l|l|l|l|}
\hline $15-17$ years & $18-20$ years & $21-23$ years & $24-26$ years & $27-29$ years & 30 years and above \\
\hline & & & & & \\
\hline
\end{tabular}

4. What is your marital status?

\begin{tabular}{|l|l|l|l|l|}
\hline Single & Married & Divorced & Separated & Others specify \\
\hline & & & & \\
\hline
\end{tabular}

5. What is your smoking status

\begin{tabular}{|l|l|l|}
\hline Non smoker & Heavy smoker & Occasional smoker \\
\hline & & \\
\hline
\end{tabular}

6. How long have you been staying in the room?

\begin{tabular}{|l|l|l|l|c|}
\hline Less than 1 month & $1-4$ months & $5-8$ months & $9-12$ months & Above 12 months \\
\hline & & & & \\
\hline
\end{tabular}

7. Within the $\mathbf{2 4} \mathbf{h}$ of a day how long on the average do you usually spend in the room?

\begin{tabular}{|l|l|l|l|l|l|}
\hline $0-4 \mathrm{~h}$ & $5-8 \mathrm{~h}$ & $9-12 \mathrm{~h}$ & $13-16 \mathrm{~h}$ & $17-20 \mathrm{~h}$ & $21-24 \mathrm{~h}$ \\
\hline & & & & & \\
\hline
\end{tabular}

8. How would you describe your mode of dressing most times while in the room?

\begin{tabular}{|l|l|l|}
\hline Formal/Official & Casual & Others specify \\
\hline & & \\
\hline
\end{tabular}

Section C (Information about user's response to the indoor environmental condition)

1. What do you regard as the most prominent heat source in the room?

\begin{tabular}{|l|l|l|l|l|}
\hline Cooking stove & Electric bulb & Direct sunlight & None & Others specify \\
\hline & & & & \\
\hline
\end{tabular}

2. Please rate your level of satisfaction with the quality of the indoor air for the past 4 weeks.

\begin{tabular}{|c|c|c|c|c|c|}
\hline i) Freshness of the air in the room & Very stuffy & Stuffy & Fair & Fresh & Very fresh \\
\hline ii) Odour in the room & Very smelly & Smelly & Fair & Odourless & Very clean \\
\hline
\end{tabular}

3. What do you regard as the most prominent source of air pollutant for the room?

\begin{tabular}{|l|l|l|l|l|l|l|l|}
\hline Toilets & $\begin{array}{l}\text { Waste bin } \\
\text { inside/outside }\end{array}$ & $\begin{array}{l}\text { Dirty } \\
\text { carpet/laundry }\end{array}$ & $\begin{array}{l}\text { Open } \\
\text { gutter }\end{array}$ & Cosmetics & $\begin{array}{l}\text { Occupants } \\
\text { body odour }\end{array}$ & None & Others specify \\
\hline & & & & & & & \\
\hline
\end{tabular}


Section D (Information about user's physical health status)

1. How often have you observed the following physical health symptoms within the last $\mathbf{4}$ weeks?

\begin{tabular}{|l|l|l|l|l|l|}
\hline & & Not at all & Occasionally & $\begin{array}{l}\text { More than half of } \\
\text { the period }\end{array}$ & $\begin{array}{l}\text { Almost every } \\
\text { day }\end{array}$ \\
\hline a & Nausea & & & & \\
\hline b & Eye irritation & & & & \\
\hline c & Skin irritation & & & & \\
\hline d & Vomiting & & & & \\
\hline e & Dizziness & & & & \\
\hline f & Headache & & & & \\
\hline g & Fatigue & & & & \\
\hline h & Sore throat & & & & \\
\hline i & Runny nose & & & & \\
\hline j & Cold & & & & \\
\hline k & Cough & & & & \\
\hline l & Respiratory problem & & & \\
\hline
\end{tabular}

2. How often did you visit the Health Centre to complain about the following physical health symptoms within the last 4 weeks?

\begin{tabular}{|l|l|l|l|l|l|}
\hline & & Not at all & Occasionally & $\begin{array}{l}\text { More than half of } \\
\text { the period }\end{array}$ & $\begin{array}{l}\text { Almost every } \\
\text { day }\end{array}$ \\
\hline a & Nausea & & & & \\
\hline b & Eye irritation & & & & \\
\hline c & Skin irritation & & & & \\
\hline d & Vomiting & & & & \\
\hline e & Dizziness & & & & \\
\hline f & Headache & & & & \\
\hline g & Fatigue & & & & \\
\hline h & Sore throat & & & & \\
\hline i & Runny nose & & & & \\
\hline j & Cold & & & & \\
\hline k & Cough & & & & \\
\hline l & Respiratory problem & & & \\
\hline
\end{tabular}

3. In general, how would you rate your physical health status or physical well-being for the past 4 weeks.

\begin{tabular}{|l|l|l|l|l|}
\hline Excellent & Very good & Good & Fair & Poor \\
\hline & & & & \\
\hline
\end{tabular}

